\title{
Assessment of Dynamic Pairwise Wake Vortex Separations for Approach and Landing at Vienna Airport
}

\author{
Frank Holzäpfel ${ }^{*}$ \\ Institut für Physik der Atmosphäre, Deutsches Zentrum für Luft- und Raumfahrt, \\ 82234 Oberpfaffenhofen, Germany \\ Lukas Strauss ${ }^{\dagger}$ \\ MeteoServe Wetterdienst GmbH / Austro Control GmbH, 1220 Vienna, Austria \\ and \\ Carsten Schwarz \\ Institut für Flugsystemtechnik, Deutsches Zentrum für Luft- und Raumfahrt, \\ 38108 Braunschweig, Germany
}

\begin{abstract}
The Wake Vortex Prediction System WSVS (WirbelSchleppenVorhersageSystem) has been developed to tactically increase airport capacity by employing dynamically adjusted aircraft separations for approach and landing without compromising safety. For this purpose the WSVS considers the involved aircraft type pairing, the prevailing weather conditions and the resulting wake vortex behavior. A Monte Carlo simulation study demonstrates that the WSVS is well adjusted to a reasonable level of safety. The simulation study evaluates the probability that wake vortices still linger within a defined radius around the follower aircraft and compares this probability to measurement data collected at five major international airports. The potential of the WSVS to optimize aircraft separations is assessed by employing nine months of traffic and weather prediction data collected at Vienna International Airport. Analyses of the separation reduction potential are established and compared to current regulations. Dependencies on prevailing headwind and crosswind conditions are discussed in terms of individual wake vortex behavior and statistical distributions of wake turbulence separations. The results indicate that substantial potential for safely reduced aircraft separations exists mainly under sufficiently strong crosswind conditions for any aircraft type combination requiring wake vortex separation minima.
\end{abstract}

\section{Introduction}

IRCRAFT trailing vortices, generated as an unavoidable consequence of lift, pose a potential risk to following aircraft. The separation standards between consecutive aircraft limit the capacity of congested airports in a rapidly growing aeronautical environment ${ }^{1,2}$. A few years ago, the International Civil Aviation Organization (ICAO) initiated a process for the optimization of wake turbulence separations termed RECAT. RECAT phase I, which is the classification into six categories considering the weight, approach speed, wing characteristics and the rolling moment exerted on following aircraft, has been implemented at selected airports in the US ${ }^{3}$ and Europe ${ }^{4}$. RECAT phase II consists of a static separation matrix of distance and time for individual aircraft types (pair-wise separations) based upon similar metrics as RECAT I. The long-term goal of the RECAT initiative (phase III) foresees dynamic pair-wise separations that consider the aircraft type pairing and the effects of the environmental conditions on wake vortex behavior.

The Wake Vortex Prediction and Monitoring System WSVBS (Wirbelschleppenvorhersage- und beobachtungssystem) has been developed to tactically increase airport capacity by employing dynamically adjusted aircraft separations for approach and landing dependent on weather conditions and the resulting wake vortex behavior without compromising safety ${ }^{\mathbf{5 , 6},}$. In this study only the predictive part of the WSVBS system is considered and the monitoring aspects are excluded. Therefore, in this paper the advisory system is simply called Wake Vortex Prediction System (WirbelSchleppenVorhersageSystem) WSVS.

\footnotetext{
* Senior Research Scientist, frank.holzaepfel@dlr.de, Senior Member AIAA

${ }^{\dagger}$ Scientist

* Research Scientist, Member AIAA
}

American Institute of Aeronautics and Astronautics 
The WSVS combines several probabilistic elements in order to make its predictions safe. In order to demonstrate that the WSVS is well adjusted to a reasonable level of safety, the probability that wake vortices still linger within a defined radius around the follower aircraft is estimated via Monte Carlo simulation and compared to measurement data collected by NASA and DLR at 5 major international airports.

Based on these results this paper assesses the potential of the WSVS to optimize separations of aircraft approaching Vienna International Airport. Nine months of traffic data comprising aircraft types and flight speeds along selected positions of the approach is retrieved from the Mode-S protocol. Meteorological data comprising vertical profiles of horizontal wind, potential temperature, and air density are taken from weather predictions of the IFS (Integrated Forecasting System) of the ECMWF (European Centre for Medium-Range Weather Forecasts). Turbulence kinetic energy (TKE) is derived from a Richardson number based approach.

The analysis covers statistics of the achievable aircraft separation reduction potential compared to the separation matrices of ICAO and RECAT-EU. The correlation between the vertical profiles of headwind and crosswind and the separation reduction potential is elaborated. Exemplary case studies on landing rates, meteorological conditions, and spatial and temporal aircraft separations as actually flown and predicted by the WSVS are introduced as examples for possible developments throughout a day. In order to better understand the mechanisms controlling the temporal aircraft separations in headwind and crosswind situations, the temporal changes of wake vortex parameters and safety areas in individual vertical WSVS prediction planes are analyzed for selected cases.

The results indicate that substantial potential for reduced separations emerges for any aircraft type combination requiring wake vortex separations under strong crosswind conditions. The WSVS predictions for strong headwinds reveal only a modest potential of separation reduction. However, the discussed headwind effects provide interesting insights with respect to time-based procedures for arrivals, which will have to be implemented at large European airports in the next 5 to 10 years.

\section{The Wake Vortex Prediction System WSVS}

Initially, the Wake Vortex Prediction and Monitoring System WSVBS has been developed to tactically increase airport capacity for approaches to the closely-spaced parallel runway system of Frankfurt airport ${ }^{5,6}$. Later the WSVBS has been extended to predict dynamic pairwise separations for landings on single runways ${ }^{7}$. Demonstration campaigns at the airports Frankfurt and Munich substantiated that the WSVBS predictions were one-hundred percent safe considering the wake vortex behavior measured by lidar for about 2000 landings. In this paper only the predictive part of the WSVBS system is considered and the monitoring aspects are excluded; therefore, we will refer to the Wake Vortex Prediction System WSVS in the remainder of this paper. In the following, the main components of the WSVS are briefly introduced and a few new developments are sketched in some more detail.

Figure 1 delineates the components of the WSVS and their interplay as they are applied to the data base available from Vienna airport. The meteorological conditions are taken from operational predictions of the IFS (Integrated Forecast System) of the ECMWF (European Centre for Medium-Range Weather Forecasts) with a model output interval of three hours. A single vertical profile of wind speed, potential temperature and air density is used to describe the meteorological conditions in all four approach corridors associated with the two airport runways. Turbulent kinetic energy (TKE) is derived from thermal stability and wind gradients employing a Richardson number based approach ${ }^{8,9}$. The TKE is translated into turbulence dissipation rate according to the approximate formula provided by Ref. 11.

The considered arrival traffic consists of 78,119 approaches and landings on the runways $11 / 29$ and 16/34 during the months November 2017 to June 2018 and October 2018. The period July to September 2018 has been omitted due to insufficient availability of aircraft type data. The aircraft data base of the WSVS contains 94 different aircraft types covering more than $95 \%$ of the arrivals at Vienna Airport. Within that traffic mix $94 \%$ correspond to medium weight class aircraft and only $6 \%$ are heavies. From Mode-S data protocols aircraft types and true airspeeds within the prediction planes of the WSVS are retrieved. Mode-S is a secondary surveillance radar process that allows selective interrogation of aircraft employing ground-based interrogators and airborne transponders ${ }^{10}$. The weights of the approaching aircraft are adjusted to $85 \%$ of the maximum landing weight (MLW). Measurements at the airports Memphis and Dallas Fort Worth demonstrate that the landing weight on average amounts to $85 \%$ of the MLW ${ }^{12}$ and other sources confirm this result ${ }^{13}$. Wing spans are gathered from the BADA (Base of Aircraft Data) data base ${ }^{14}$ and MLWs mainly from type certificate data sheets (TCDS, from EASA/ FAA/ CAA) and Airplane Characteristics for Airport Planning (from Airbus and Boeing).

A merger of fits of glide path adherence statistics from different sources collected at the airports Frankfurt, St. Louis, Atlanta, and Chicago is used to define the dimensions of the flight corridors in terms of standard deviations 
from the nominal glide paths ${ }^{7}$. The WSVS concept requires that all aircraft are established on the glide slope at the final approach fix (FAF) which is considered $11 \mathrm{~nm}$ before the touchdown zone (TDZ) for this study. Wake vortex evolution is predicted within 15 gates along the final approach (see Table 1). In ground proximity the gate separation of $1 \mathrm{~nm}$ is first reduced to $1 / 3 \mathrm{~nm}$ and then to $1 / 6 \mathrm{~nm}$ to properly resolve the interaction of wake vortices with the ground. The WSVS prediction planes are transported by the prevailing headwind respectively tailwind allowing for a realistic modeling of wake vortex behavior in ground proximity. This constitutes an important aspect for the simulation of landings, because wake vortex encounters at low altitudes appear more frequently in tailwind situations ${ }^{15}$.

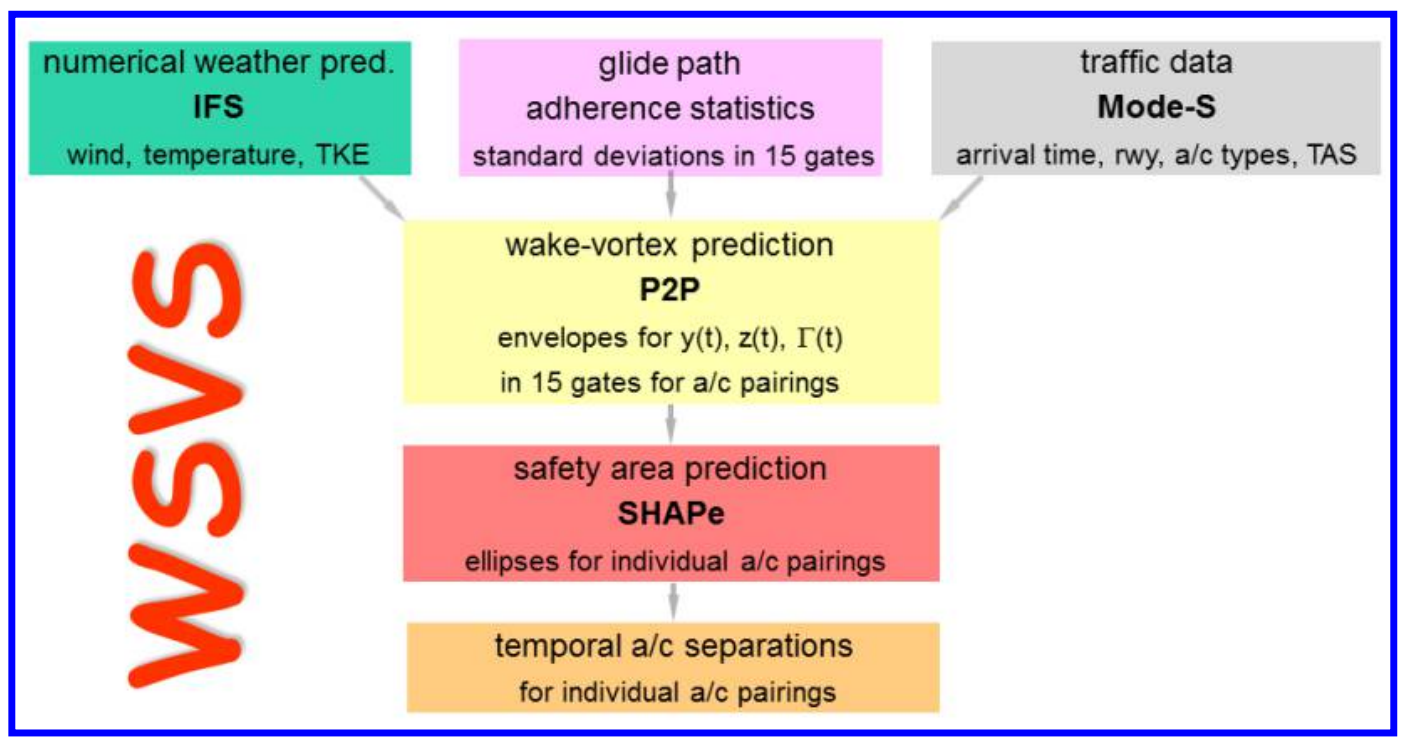

Figure 1 Flowchart of the WSVS.

Table 1 Initial gate (prediction plane) center positions along glide path in geodetic coordinates (origin in touchdown zone).

\begin{tabular}{cccc}
\hline \hline gate No & $\mathrm{x}_{\text {gate }}[\mathrm{nm}]$ & $\mathrm{X}_{\text {gate }}[\mathrm{m}]$ & $\mathrm{Z}_{\text {gate }}[\mathrm{m}]$ \\
\hline 1 & -11 & -20372 & -1077 \\
2 & -10 & -18520 & -979 \\
3 & -9 & -16668 & -880 \\
4 & -8 & -14816 & -781 \\
5 & -7 & -12964 & -683 \\
6 & -6 & -11112 & -584 \\
7 & -5 & -9260 & -486 \\
8 & -4 & -7408 & -387 \\
9 & -3 & -5556 & -289 \\
10 & -2 & -3704 & -191 \\
11 & -1.5 & -2778 & -142 \\
12 & -1 & -1852 & -94 \\
13 & $-2 / 3$ & -1235 & -61 \\
14 & $-1 / 3$ & -617 & -29 \\
15 & $-1 / 6$ & -309 & -13 \\
\hline \hline
\end{tabular}


Based on the meteorological and traffic input data the Probabilistic Two-Phase wake-vortex decay model (P2P) predicts upper and lower bounds for position and strength of the vortices. The basic P2P model design as well as some applications, assessments and further developments are reported in Refs. 16, 17, 18, and 19. P2P considers all effects of the leading-order impact parameters ${ }^{20}$ : aircraft parameters (span, weight, velocity, and trajectory), wind (crosswind and headwind components), wind shear, turbulence, temperature stratification, and ground proximity. P2P has been validated against in-ground effect and out-of-ground effect measurement data of four US and nine European field measurement campaigns comprising about 15,000 individual cases.

The bounds predicted by P2P are expanded by the safety area around a vortex that must be avoided by follower aircraft for safe and undisturbed flight (SHAPe). The Simplified Hazard Area (SHA) concept ${ }^{21,22}$ assumes that, for encounters during approach and landing, the vortex-induced rolling moment constitutes the dominant effect and can be used to define a safety area representing the entire aircraft reaction. Then encounter severity can be characterized by a single parameter, the Roll Control Ratio, RCR, which relates the wake vortex induced rolling moment to the maximum available roll control power. Following full flight simulator investigations as well as real flight tests RCR is adjusted to 0.2 (Ref. 23).

In every gate several ellipses are defined (see Figure 2) representing the approach corridor (green), the vortex area prediction (blue), and the safety area prediction (red). The respective sums of the vertical and horizontal probabilistic allowances of these components define the dimensions of the resulting safety ellipse. The instant when all the resulting safety ellipses along the glideslope do not overlap anymore with the elliptical approach corridor defines the temporal minimum wake-vortex separation between an individual aircraft pairing ${ }^{5,7}$. For operational purposes, the maximum of three time thresholds, the WSVS separation, the minimum radar separation, and the runway occupancy time, would then constitute the applicable separation. In this study, however, these additional criteria are neglected to allow an independent consideration and comparison of the three time thresholds. The maximum prediction time of the WSVS is adjusted to $180 \mathrm{~s}$.

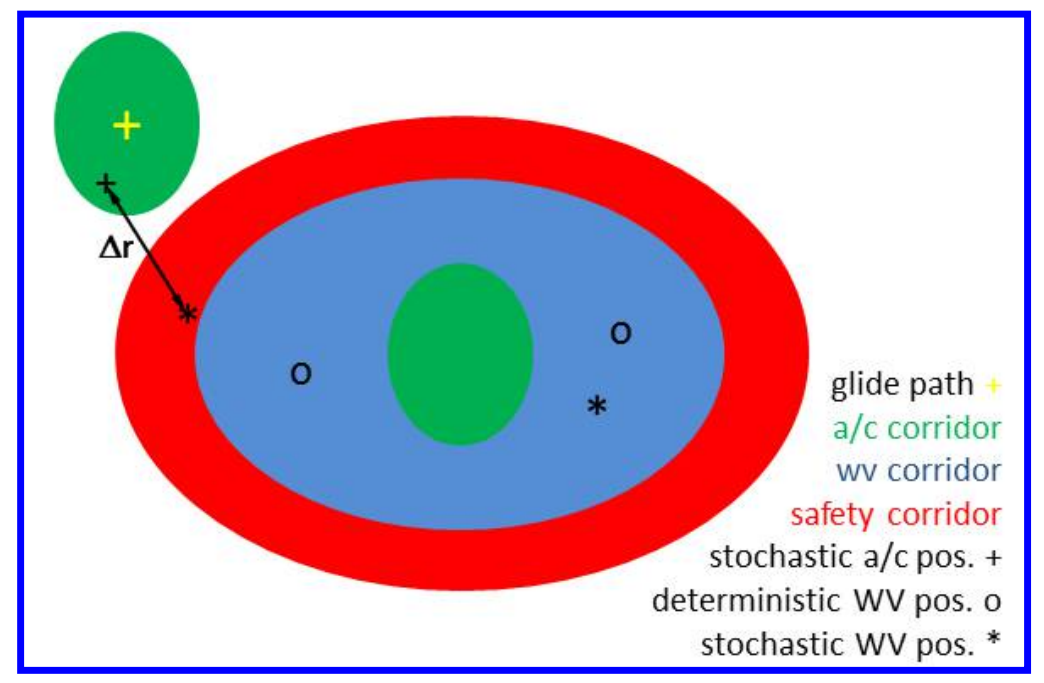

Figure 2 Scheme illustrating the elements of the Monte Carlo simulation for one landing.

\section{How Conservative are the WSVS Predictions Compared to Current Practice?}

The WSVS combines several probabilistic elements in order to make its predictions safe. One key element of its current setup is that the WSVS adds to the one- $\sigma(68.3 \%)$ aircraft approach corridor one- $\sigma$-allowances resulting from the variability of wake vortex behavior (P2P) and adds finite safety separation distances (SHAPe) (see Figure 2). The instant of time when this area, consisting of three ellipses, does not overlap anymore with the aircraft corridor in all gates determines the WSVS aircraft separations. However, neither the probability that the wake vortices including their individual safety area reside within the predicted elliptical total safety area nor the probability that the wake vortices may still reside in the flight corridor or actually come close to a follower aircraft are known. The latter probability is the most relevant one for the degree of safety of the advisory system. So the probability that wake vortices still linger within a defined radius around the follower aircraft is estimated in this section and compared to measurement data collected by NASA and DLR at 5 major international airports. 
More precisely, Monte Carlo simulation is employed in order to establish statistics of the distances between a landing aircraft and the closest wake vortex generated by a leading aircraft at the separation time suggested by the WSVS. These distances are compared to those found within the analysis of lidar measurements and aircraft data described in Ref. 24. The lidar study employs data of 8056 landings collected at the airports Dallas, Denver, Frankfurt, Memphis and Munich. During the Memphis 2013 campaign RECAT separations ${ }^{3}$ were applied while during the other campaigns ICAO separations ${ }^{25}$ were applicable. The analysis of the lidar observations reveals that, in at least $1.5 \%(3.7 \%)$ of the landings in which the measured vortices were generated in an altitude of about $50 \mathrm{~m}$, the luff vortex remains within a distance of $25 \mathrm{~m}(50 \mathrm{~m})$ to the follower aircraft within a temporal buffer of $\pm 10 \mathrm{~s}$ of flyby. This finding is considered as a reference for the current practice.

The lidar study considers only wake vortices with circulation strengths above $50 \%$ of their initial value because most vortices with a circulation less than half of their initial circulation cannot be tracked anymore. As a consequence, many encounters with less coherent vortices are not included in the above stated encounter percentages and the real encounter rates will be higher. Note that here the term encounter is used for situations with distances of up to $50 \mathrm{~m}$ between fuselage and vortex center. Hence, the term encounter is also used for cases without any vortex effect on the passing aircraft.

In the Monte Carlo simulation we only exclude wake vortices with circulation values below $50 \mathrm{~m}^{2} / \mathrm{s}$. Below this value the evaluation of the circulation of the vortices is usually not possible anymore due to a loss of coherence of the vortex structure. Also, for circulation values below $50 \mathrm{~m}^{2} / \mathrm{s}$ the safety areas to be avoided according to the SHAPe concept become very small such that in practice they would not be relevant to safety anymore. We further set the minimum vortex age to $60 \mathrm{~s}$ as a value supporting minimum radar separations of $2.5 \mathrm{~nm}$. Operationally WSVS separations below $60 \mathrm{~s}$ would not be applicable and adjusted upward to $60 \mathrm{~s}$. In the real-world reference data ${ }^{24}$ separation times vary between $80 \mathrm{~s}$ and $500 \mathrm{~s}$.

Figure 2 illustrates the elements employed in the Monte Carlo simulation conducted for the 78.119 aircraft pairings of the Vienna data base. For the instant of time when all safety corridors do no longer overlap with the aircraft corridors, stochastic aircraft positions and wake vortex positions are generated for the flight altitude of $50 \mathrm{~m}$ above ground targeted by the lidar study. The follower aircraft position is computed as random deviation from the glide path position using the fits of glide path adherence statistics introduced in the previous section. The stochastic wake vortex positions are generated employing the deterministic vortex positions and the respective standard deviations predicted by the P2P model. Figure 3 delineates the resulting wake vortex positions with respect to the follower aircraft positions (centered in the origin) at the aircraft separation times suggested by the WSVS.

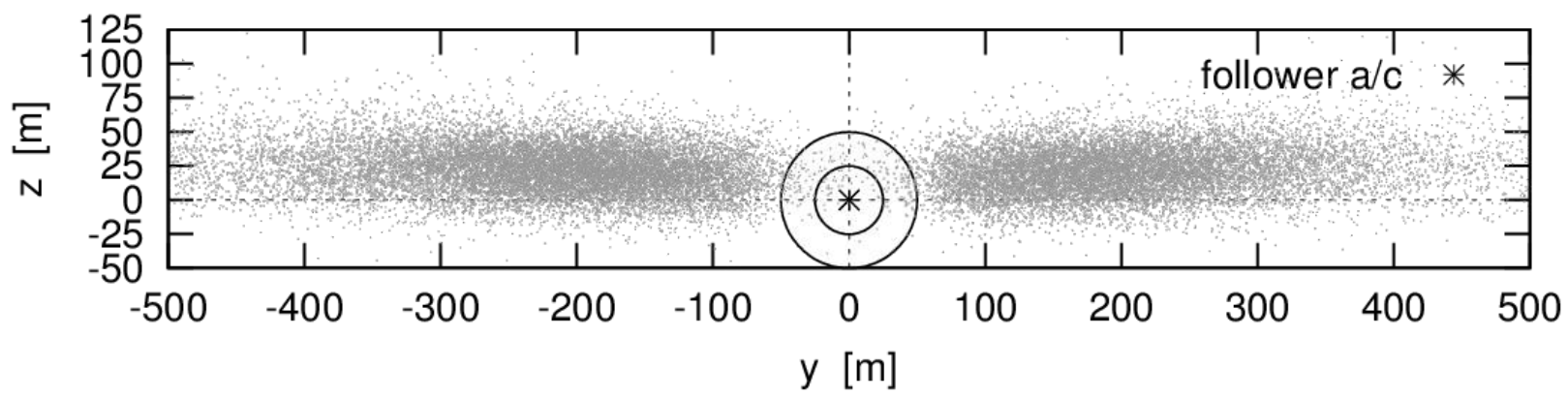

Figure 3 Scatter plot of vortex positions relative to follower aircraft at predicted WSVS aircraft separation times. Circles represent $25 \mathrm{~m}$ and $50 \mathrm{~m}$ distances between follower aircraft and wake vortices evaluated in this study.

From this data the distance between the aircraft position and the closest neighboring vortex position, $\Delta \mathrm{r}$, is determined. The distribution of the distances, $\Delta \mathrm{r}$, is compared to the findings from the lidar airport trials. For the WSVS predictions wake vortices still reside within a distance of $50 \mathrm{~m}$ to the follower aircraft in $1.3 \%$ of the landings. This is about three times less frequent than the $3.7 \%$ estimated by the lidar data analysis. The respective values for a $25 \mathrm{~m}$ radius are $0.25 \%$ for the Monte Carlo simulation and $1.5 \%$ for the real-world reference. Based on this even more safety relevant measure, wake encounters with WSVS separations would be even 6 times less frequent than in daily routine without a wake vortex advisory system. For example, the Frankfurt wake vortex warning system considered a $30 \mathrm{~m}$ distance between fuselage and wake vortices as a critical gap differentiating between acceptable and critical encounters ${ }^{26}$.

Another unpublished reference consists of long-term lidar measurements of wake vortices at Charles de Gaulle Airport suggesting that in $3 \%$ of the cases the vortices were at least as close as $25 \mathrm{~m}$ in radial distance to the following 
landing aircraft in proximity of the threshold ${ }^{\S}$. Using this finding as a reference to the current simulations must be done with care, because the details of the measurement situation are not known and may deviate from those applied for the Monte Carlo analysis. But it can be considered an additional source suggesting that the chosen settings of the WSVS may deliver reasonably safe pairwise dynamic aircraft separations.

\section{WSVS Predictions for Windy Days}

For three selected days of the total period considered, case studies on the actually flown aircraft separations during final approach at Vienna airport and the respective separations predicted by the WSVS are depicted in Figure 4 to Figure 6 together with the prevailing meteorological conditions. Panel (a) of the respective figure plots the number of landing aircraft per hour where blue bars denote the fraction of light (L) and medium (M) aircraft and red bars denote the fraction of the heavy $(\mathrm{H})$ and super-heavy $(\mathrm{J})$ aircraft. Panel (b) displays the vertical profiles of potential temperature, a parameter controlling wake vortex descent distances and decay rates ${ }^{20}$. Panel (c) shows the predicted vertical wind profiles in terms of wind barbs and color-coded headwinds, where winds in flight direction have a positive sign. Wind barbs show both wind direction and speed where each half flag depicts $5 \mathrm{kt}$ and each full flag $10 \mathrm{kt}$. Panel (d) displays color-coded crosswind profiles and is otherwise equivalent to panel (c). Panel (e) denotes hourly distributions of the spatial separations of the landing aircraft pairs derived from Mode-S aircraft position data. The spatial separation between aircraft is determined at the instant when the leader passes the runway threshold. Several significant percentiles of the aircraft separations are denoted as follows: black lines $\left(0^{\text {th }}\right.$ and $100^{\text {th }}$ percentile), light gray bars $\left(5^{\text {th }}\right.$ and $95^{\text {th }}$ percentile $)$, dark gray bars $\left(25^{\text {th }}\right.$ and $75^{\text {th }}$ percentile) and red dashes for the medians. The separations behind leading aircraft of the categories $\mathrm{H}$ and $\mathrm{J}$ are denoted individually by blue dots. The blue dotted horizontal line indicates the separation between heavy and medium aircraft prescribed by ICAO whereas the minimum radar separation of $2.5 \mathrm{~nm}$ is highlighted in gray. Panel (g) corresponds to the same illustration for the WSVS predictions. Here the temporal WSVS separations, $\mathrm{t}_{\text {sep }}$, are translated into spatial separations by computing the distance between Mode-S positions of the follower aircraft at its touchdown and at $t_{\text {sep }}$ before touchdown. Panels (f) and (h) correspond to (e) and (g) for temporal aircraft separations. Highlighted in gray are minimum separations of 1 min corresponding to our approximation of minimum radar separation (see section III).

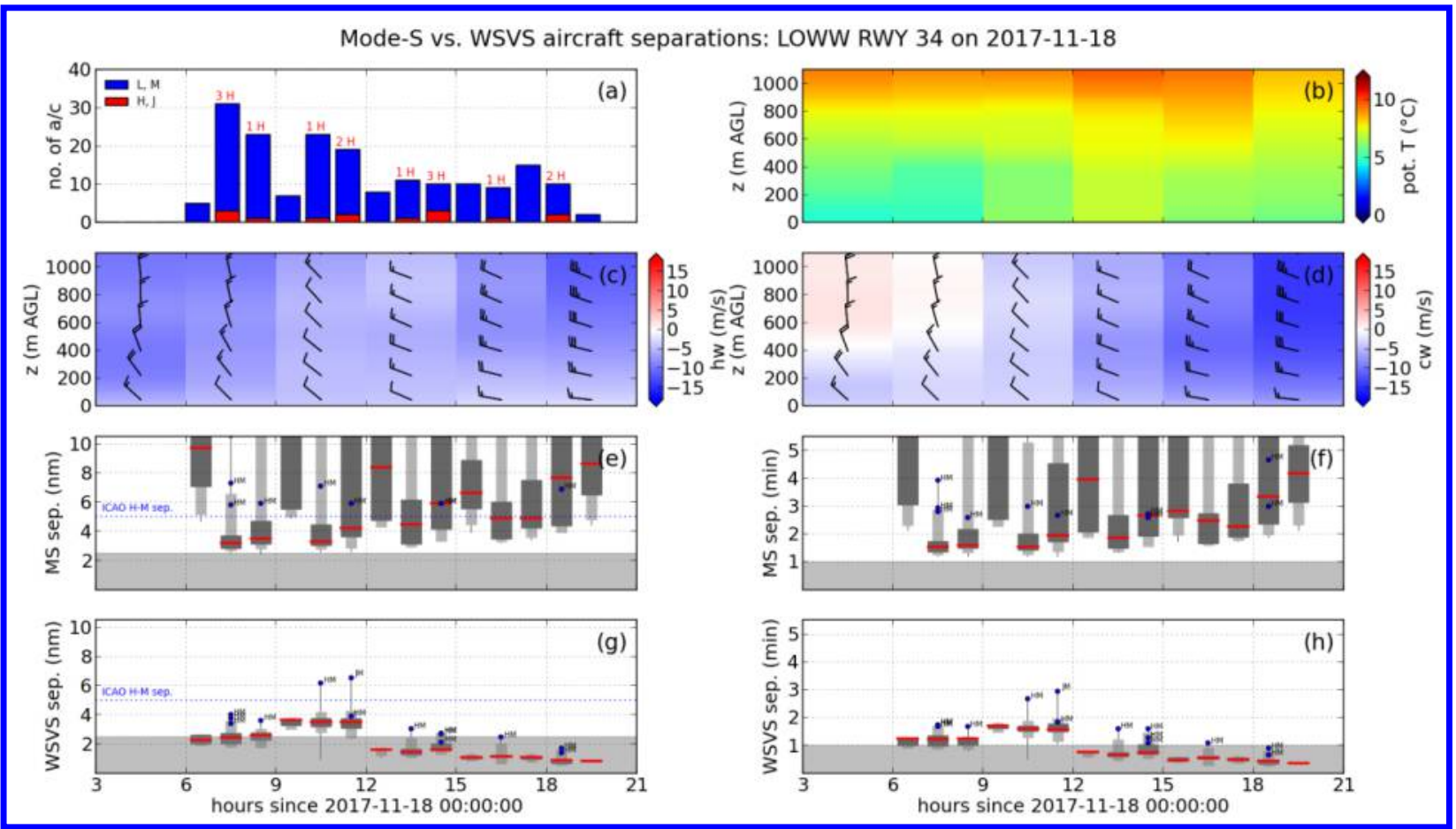

Figure 4 Survey on landing rates, meteorological conditions, spatial and temporal aircraft separations as actually flown and predicted by the WSVS for runway 34 on 18 November 2017.

\footnotetext{
$\S$ Personal communication with Vincent Treve (EUROCONTROL) during WakeNet3-Europe Workshop, London, 2011.
} 
Figure 4 shows a diurnal survey on landing rates, meteorological conditions, and aircraft separations for landings on runway 34 on 18 November 2017. As in the cases presented in Figure 5 and Figure 6, the moderate landing rates throughout most of the day are far below the maximum capacity of the airport of 44 landings per hour. During phases of rather low demand there is no need for controllers to stagger aircraft optimally. Nevertheless, times of higher demand are clearly correlated with smaller aircraft separations, as it is the case on 18 Nov 2017 between 7 and 9 UTC (local morning) (see Figure $4 \mathrm{e}$ and f).

Figure 4 demonstrates nicely how the wind conditions impact the WSVS separation reduction potential. Between 6 and 12 UTC sign changes within the crosswind profiles prevent that the vortices are blown out laterally of the flight corridor in some of the WSVS computation gates. Headwinds increase with height from about -3 to $-10 \mathrm{~m} / \mathrm{s} \mathrm{such}$ that these gates are released earlier by vortex descent. Due to the headwind advection against flight direction the vertical distance between the vortices and the tilted glide path increases with time which can be considered a favorable wake altitude adjustment equivalent (see section V.A.). Eventually, crosswind advection in ground proximity controls the resulting WSVS separations. Between 6 and 9 UTC the slightly stronger surface crosswinds of $-1.7 \mathrm{~m} / \mathrm{s}$ enable somewhat shorter separations compared to the weaker surface crosswinds of only $-1.2 \mathrm{~m} / \mathrm{s}$ prevailing afterwards. The most interesting change in wind conditions occurs starting at 12 UTC (local noon), when the crosswind strength increases all along the vertical profiles. After 18 UTC surface crosswinds of $-3.6 \mathrm{~m} / \mathrm{s}$ even enable separations below the minimum radar separation behind leading heavy aircraft.

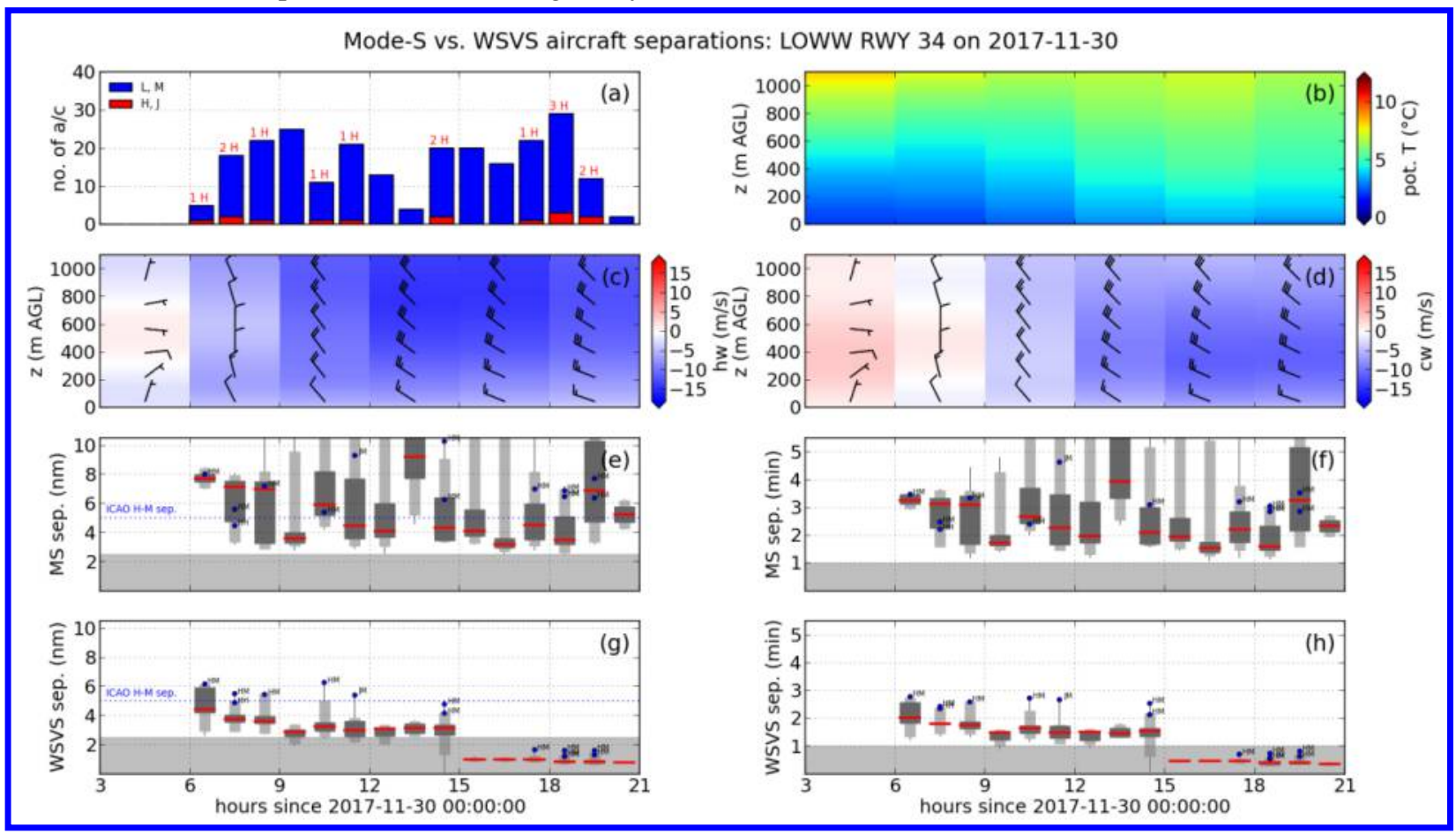

Figure 5 Survey on landing rates, meteorological conditions, spatial and temporal aircraft separations as actually flown and predicted by the WSVS for runway 34 on 30 November 2017.

Figure 5 shows the survey on landing rates, meteorological conditions, and aircraft separations for runway 34 on 30 November 2017. This day comprises the examples of wake vortex predictions discussed in the next section in Figure 7 to Figure 12. In the first three-hour time block, 6-9 UTC, the surface crosswinds are close to zero yielding no separation reduction potential compared to ICAO separations. Later on, from 9 to 15 UTC, surface crosswinds on the order of $-1.2 \mathrm{~m} / \mathrm{s}$ slightly improve the separation reduction potential. The single extraordinarily small WSVS separation value of only $5 \mathrm{~s}$ is attributed to a Cessna Citation aircraft (ICAO Doc 8643 Aircraft Type Designator: C525) following a Cessna Citation Excel (C56X) between 14 and 15 UTC with a maximum landing weight of only $8.5 \mathrm{t}$. Only after 15 UTC surface crosswinds of $-3.8 \mathrm{~m} / \mathrm{s}$ and similar strength aloft combined with headwinds above $3 \mathrm{~m} / \mathrm{s}$ enable separations below $1 \mathrm{~min}$ for all aircraft, including heavy leaders. 
Figure 6 depicts the situation for 4 December 2017 where surface headwinds above $-3.6 \mathrm{~m} / \mathrm{s}$ and surface crosswinds above $-4.1 \mathrm{~m} / \mathrm{s}$ combined with substantially higher values aloft for both wind components prevail consistently between 6 and 21 UTC. This constitutes an example where the wind conditions would enable adjusting minimum radar separations for all landing aircraft throughout the day including super heavy leaders followed by medium weight class aircraft.

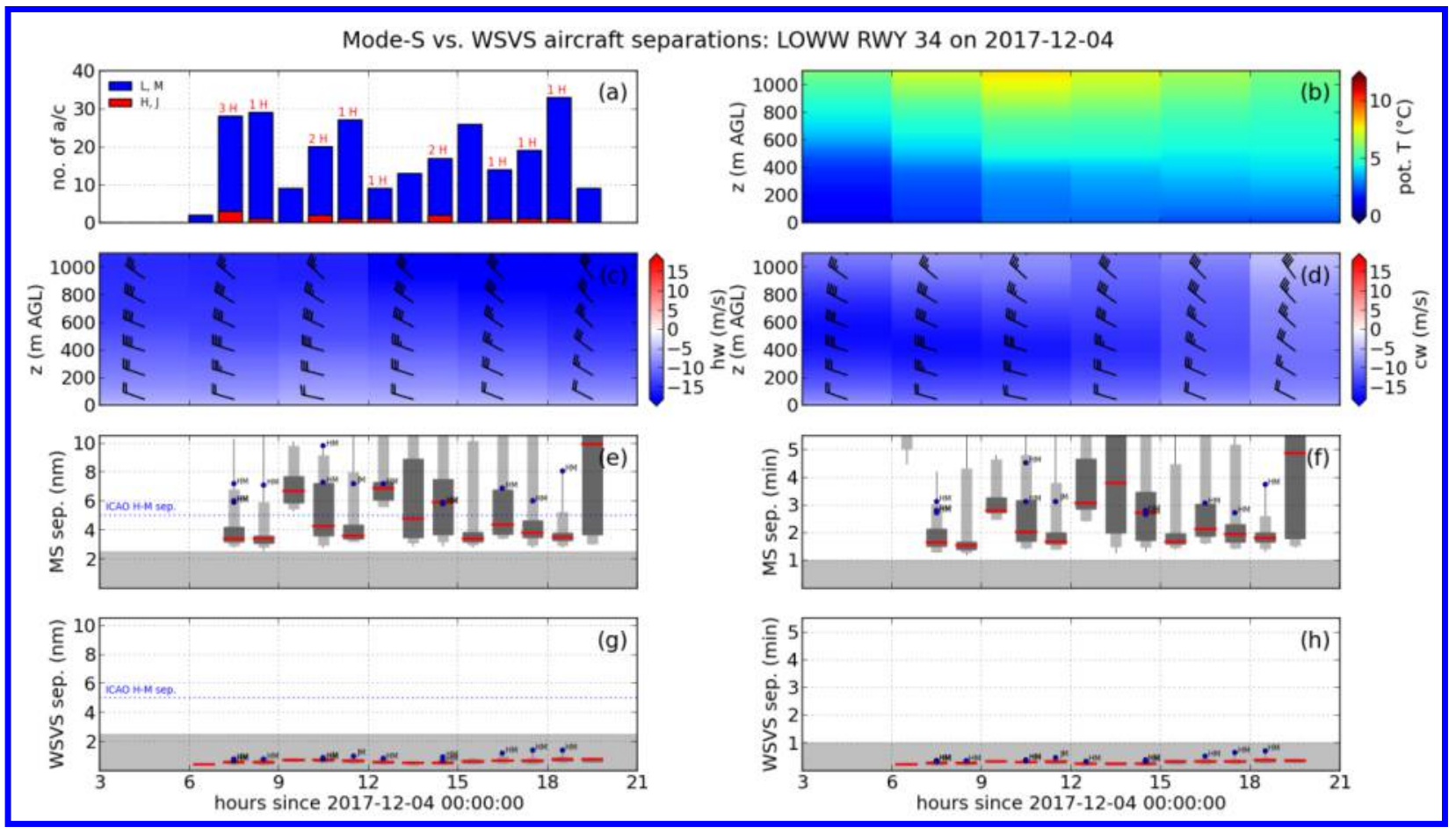

Figure 6 Survey on landing rates, meteorological conditions, spatial and temporal aircraft separations as actually flown and predicted by the WSVS for runway 34 on 4 December 2017.

\section{Wind Effects on Aircraft Separations}

\section{A. Headwind}

To better understand the mechanisms controlling temporal aircraft separations in headwind situations we take a closer look at a few selected cases. Figure 7 to Figure 9 depict the wake vortex parameters (deterministic predictions of port (magenta) and starboard (blue) vortex and probabilistic one- $\sigma$ envelope (green)) and safety areas (red) for a leading CRJ9 followed by an A320 resulting in the shortest separation of $83.6 \mathrm{~s}$ predicted within the time block from 6-9 UTC on 30 November 2017 (cf. Figure 5). The vertical profiles of the meteorological parameters displayed in the following figures (lower right panels) are normalized employing characteristic wake vortex scales ${ }^{16}$. Here $\mathrm{u}^{*}$ denotes the normalized longitudinal wind component which is positive in flight direction, $\mathrm{v}^{*}$ the crosswind, $\mathrm{q}^{*}$ the turbulence velocity, $\mathrm{N}^{*}$ the Brunt-Väisäla frequency characterizing thermal stability, and $\varepsilon^{*}$ the turbulence energy dissipation rate. Velocities are normalized by the initial wake vortex descent speed, $w_{0}$, the Brunt-Väisäla frequency with the initial time, $t_{0}$, the vortices need to descend one vortex separation, $b_{0}$, and the dissipation rate with $\mathrm{b}_{0}{ }^{1 / 3} / \mathrm{w}_{0}$.

The instant when all the resulting safety areas (red) along the glideslope have escaped from the approach corridor (dotted lines) either vertically or laterally defines the temporal separation between an individual aircraft pairing. The gates aloft without ground effects are first cleared from wake vortices by vortex descent. For example, in gate 7, displayed in Figure 7, the probabilistic vortex area predicted by the $\mathrm{P} 2 \mathrm{P}$ model exits the approach corridor at $24 \mathrm{~s}$ and the safety area predicted by the SHAPe model exits the approach corridor at $47 \mathrm{~s}$. So considering only gate 7 , aircraft separations could be adjusted to $47 \mathrm{~s}$. 
The prevailing headwind of about four vortex descent speeds $(\mathrm{u} \approx-4.7 \mathrm{~m} / \mathrm{s})$ accelerates the unblocking of the approach corridor. Due to the headwind advection against flight direction the vertical distance between vortex area and the $3^{\circ}$ glide path increases with time which is reflected by the tilted approach corridor plotted in Figure 7, upper left panel. Laterally the approach corridor is cleared from the safety area only at $137 \mathrm{~s}$ due to the weak prevailing crosswind (Figure 7, upper right panel). The upper one- $\sigma$ bound (green) of the circulation evolution falls below the deterministic prediction (blue) during the onset of rapid decay owing to the method employed for the training of the probabilistic bounds with measurement data. The lower circulation envelopes are not shown, because they are not used for the WSVS predictions.
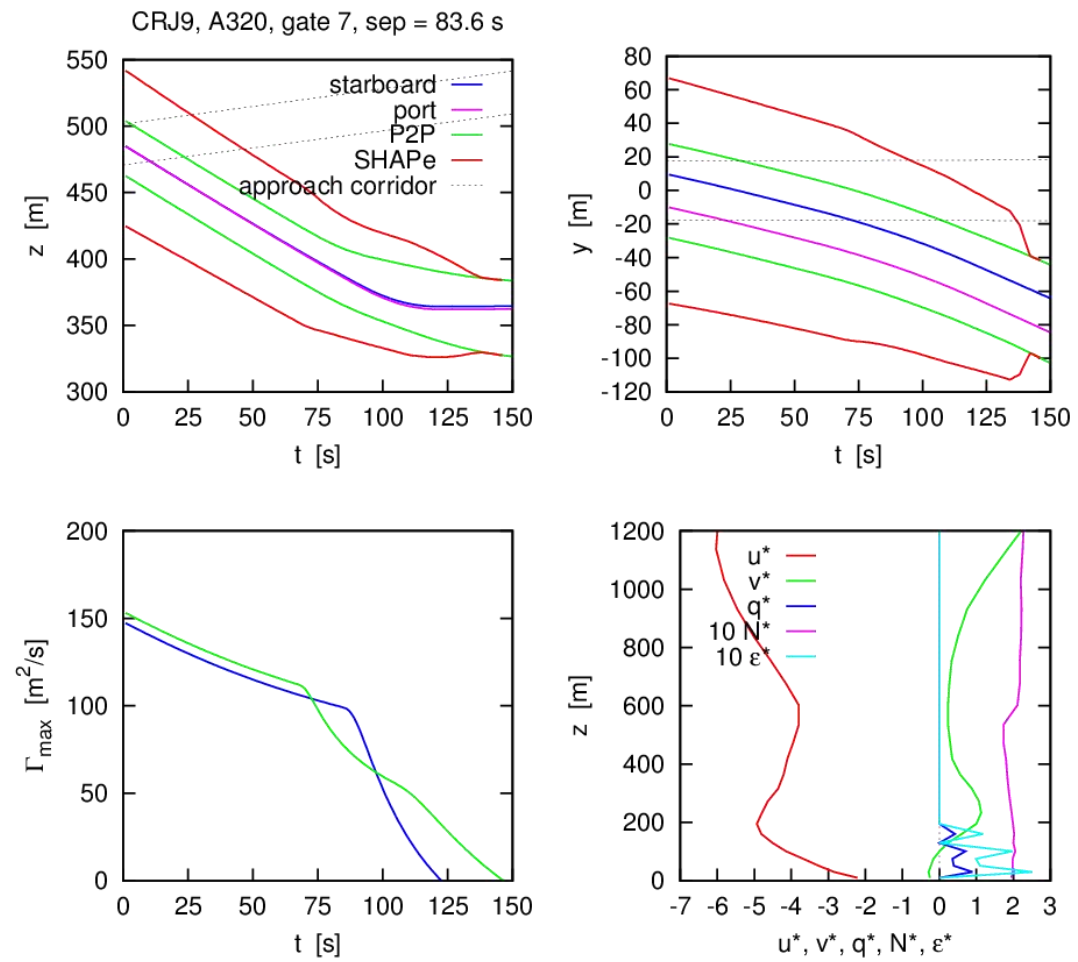

Figure 7 WSVS prediction of wake vortex parameters, safety areas and meteorological parameters for a leading CRJ9 followed by an A320 in gate 7.

Figure 8 displays WSVS predictions in ground proximity in gate 14. Due to the interaction with the ground, vortex descent is limited. Instead the vortices diverge and rebound ${ }^{19,27}$ such that the upper probabilistic bound resides eventually slightly below $30 \mathrm{~m}$. Due to the headwind transport the shrinking safety area exits the approach corridor at about $77 \mathrm{~s}$. Due to weak crosswinds and vortex divergence in ground proximity even the probabilistic vortex envelopes don't leave the approach corridor laterally.

Figure 9 illustrates that in the lowest gate 15 the safety area cannot exit the approach corridor vertically within a relevant period of time despite the headwind effect due to vortex rebound and the low flight altitude. Now the aircraft separation is controlled by vortex decay. At $84 \mathrm{~s}$ the vortices have decayed sufficiently that the following A320 aircraft may land without compromising safety. So with weak crosswind and intermediate headwind strengths aircraft separations are controlled by vortex decay in close ground proximity.

There are also a few cases where the headwind transport is not sufficient to transport the vortices out of the approach corridor even in gate 14. In that situation vortex decay in gate 14 determines the aircraft separations because the vortices generated at very low altitudes above ground (in gate 15) decay faster. 

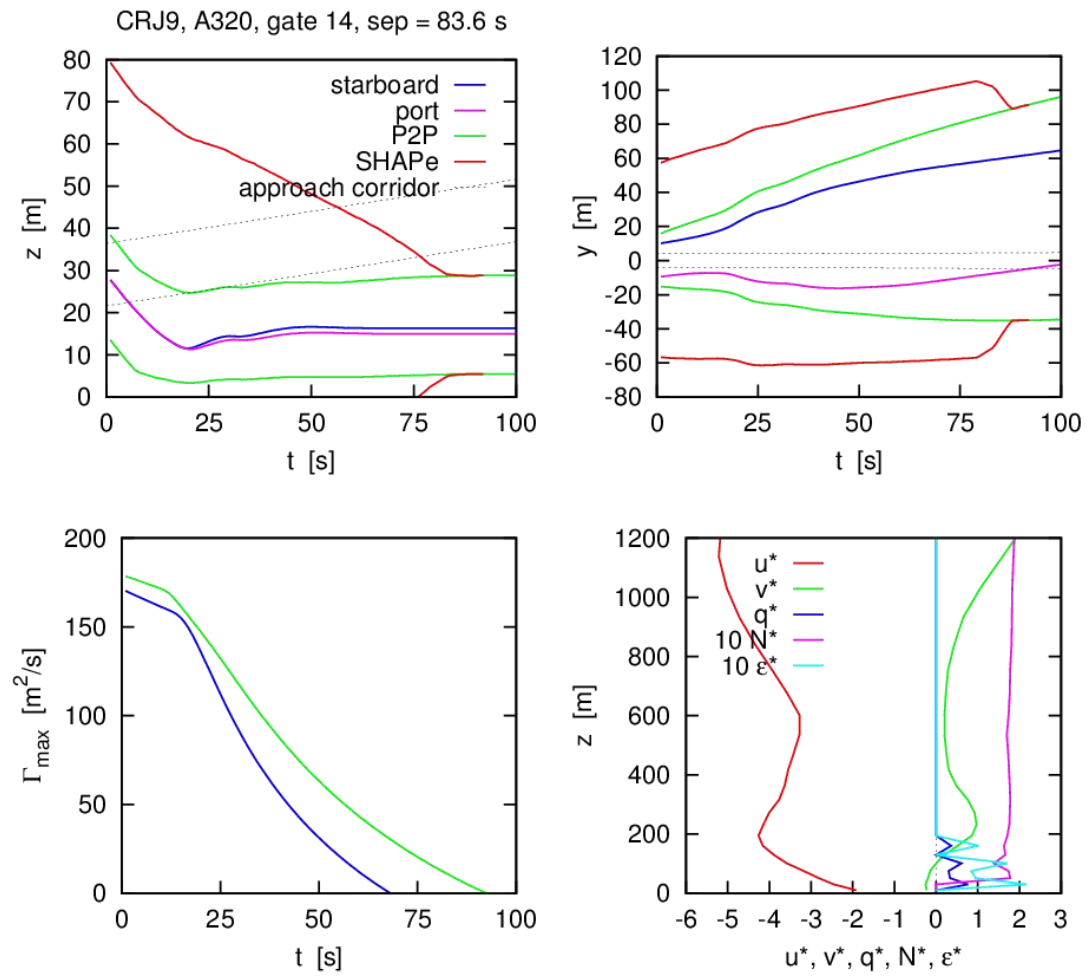

Figure 8 WSVS prediction of wake vortex parameters, safety areas and meteorological parameters for a leading CRJ9 followed by an A320 in gate 14 .
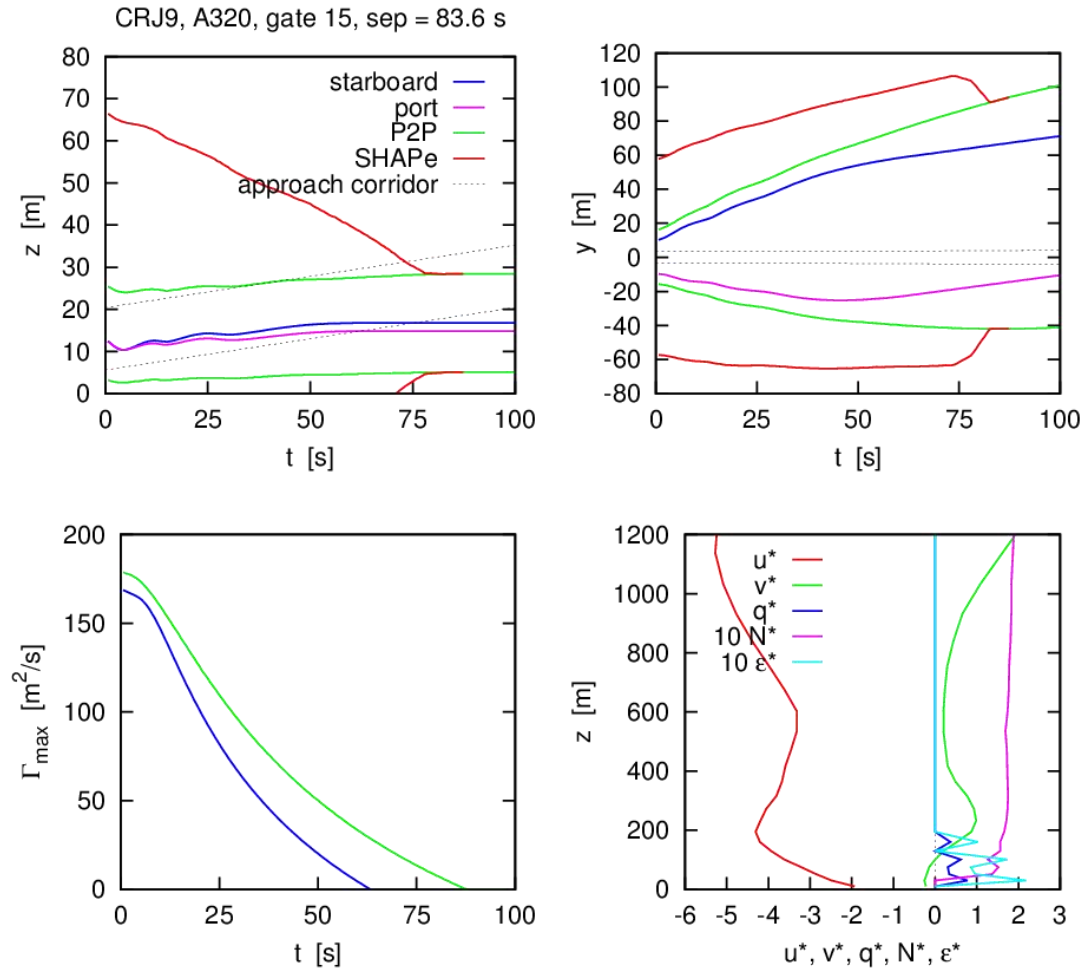

Figure 9 WSVS prediction of wake vortex parameters, safety areas and meteorological parameters for a leading CRJ9 followed by an A320 in gate 15. 

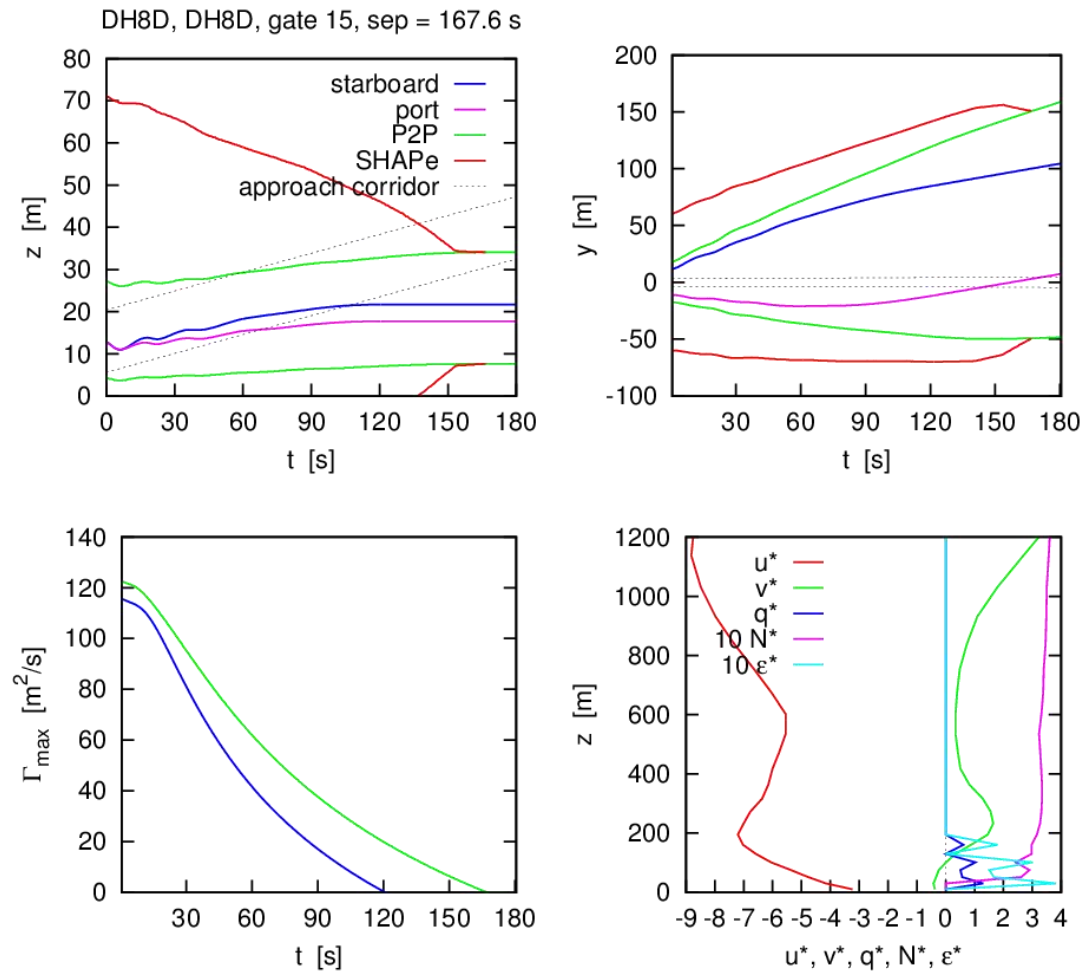

Figure 10 WSVS prediction of wake vortex parameters, safety areas and meteorological parameters for a leading DH8D followed by another DH8D in gate 15 .

Figure 10 demonstrates that vortex decay in close ground proximity may vary considerably for different even medium sized aircraft. For the aircraft pairing DH8D/DH8D the vortices have decayed sufficiently only at $168 \mathrm{~s}$. Vortex decay scales with the characteristic vortex time $\mathrm{t}_{0}$ which amounts to $14 \mathrm{~s}$ for the CRJ9 and to $27 \mathrm{~s}$ for the DH8D. The relatively high (low) characteristic vortex time of the DH8D (CRJ9) results from its relatively large (small) span of $28.4 \mathrm{~m}(24.8 \mathrm{~m})$ in relation to its low (high) weight of $28 \mathrm{t}(34 \mathrm{t})$.

During conditions in which aircraft separations are controlled by vortex decay in ground proximity, aircraft separations could be reduced by the installation of plate lines at the runway ends. Lidar measurements indicate that this way the lifetime of the most long-lived and strongest vortices can be reduced by one third ${ }^{28}$. In the framework of the SESAR2020 project PJ02 EARTH a measurement campaign at Vienna airport, scheduled for 2019, shall demonstrate that plate lines can be installed in runway proximity at an international airport and it shall be determined to which extent vortex lifetime can be shortened for various aircraft types and environmental conditions.

\section{B. Crosswind}

After 15 UTC on 30 November 2017 the wind direction has turned such that the vortex separations are controlled by lateral transport of the wake vortices out of the flight corridor (see Figure 5). The crosswind profile exhibits a maximum absolute value $(u=-11.4 \mathrm{~m} / \mathrm{s})$ at an altitude of $367 \mathrm{~m}$ and minimum absolute values $(-4.4 \mathrm{~m} / \mathrm{s})$ both at the ground and at the beginning of the considered glide path. Depending on the aircraft size either gate 1 or gate 15 (both close to the crosswind minima) control reduced aircraft separations.

Figure 11 shows an example for a leading medium aircraft. Here the safety areas leave gate 1, which has the widest flight corridor, laterally at a vortex age of $23 \mathrm{~s}$. In all other gates the flight corridor is cleared earlier due to its smaller width and the mostly larger crosswind. Figure 12 displays an example with a leading B744 where the safety area ultimately quits the lowest gate 15 at $39 \mathrm{~s}$. For big aircraft in this meteorological situation the larger initial vortex separation and vortex divergence in ground proximity are decisive. In such cases the aircraft separations could be reduced from $5 \mathrm{~nm}$ (ICAO separation) to a minimum radar separation of $2.5 \mathrm{~nm}$ for leading heavy aircraft followed by mediums. 

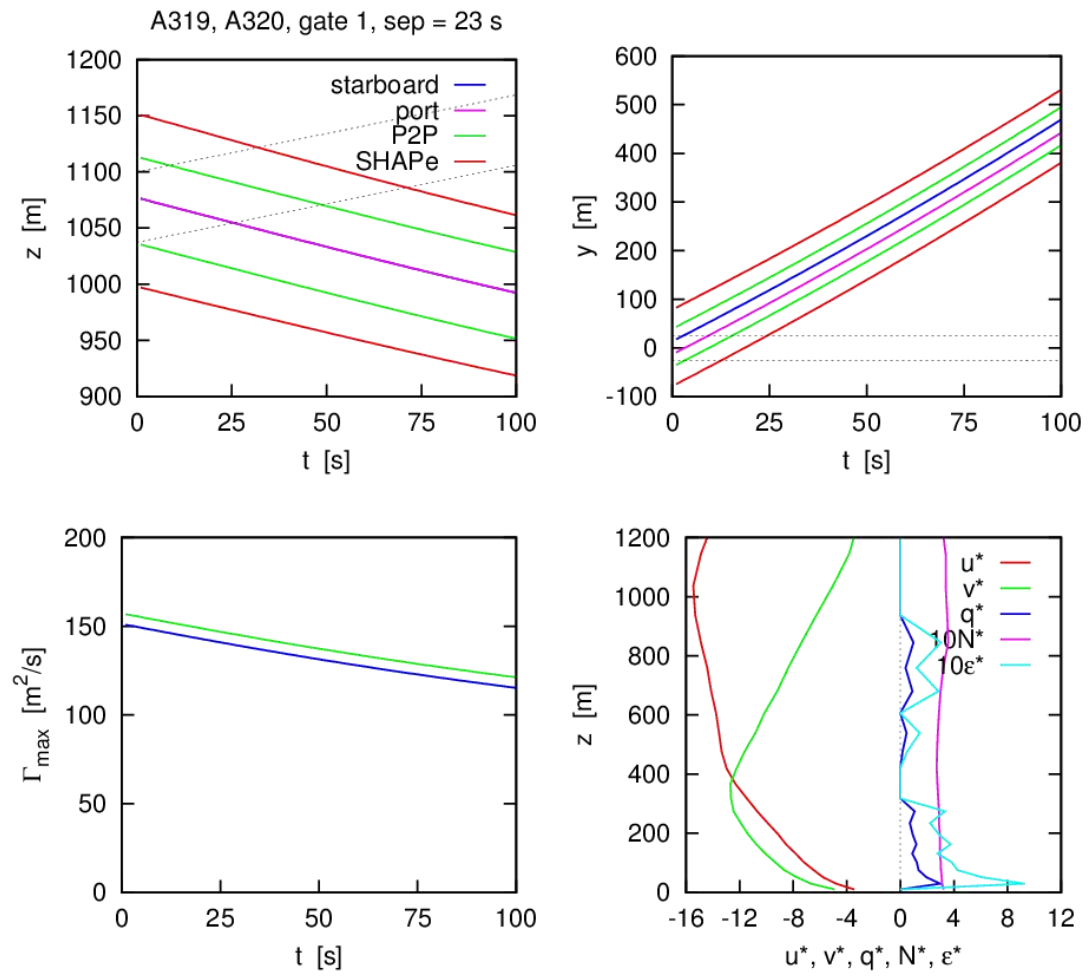

Figure 11 WSVS prediction of wake vortex parameters, safety areas and meteorological parameters for a leading A319 followed by an A320 in gate 1.
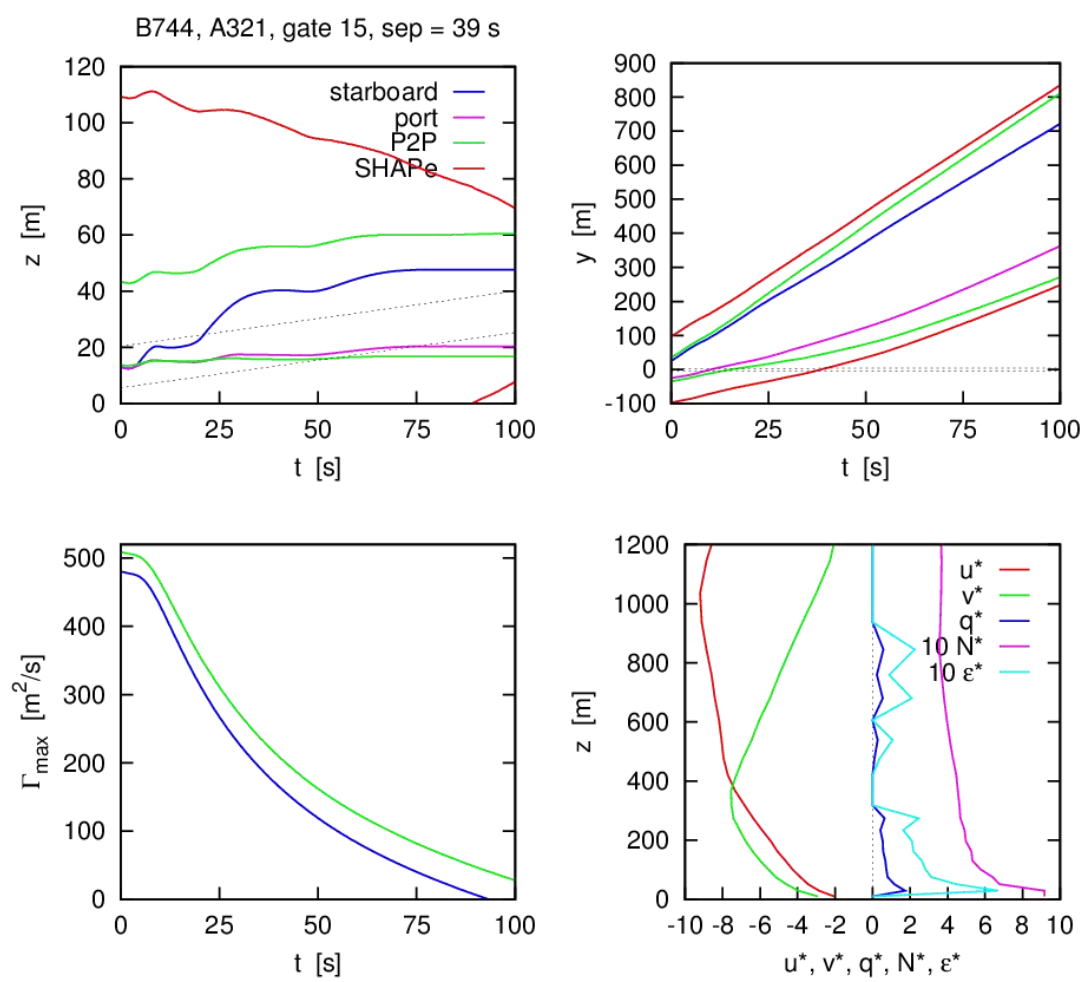

Figure 12 WSVS prediction of wake vortex parameters, safety areas and meteorological parameters for a leading B744 followed by an A321 in gate 15 . 


\section{Veering Winds}

The direction of the wind varies with the height above ground. According to the concept of the Ekman spiral the wind direction turns to the right with increasing height as it is the case in Figure 11 to Figure 14. Above the atmospheric boundary layer with a thickness on the order of $1 \mathrm{~km}$, the wind direction is mainly controlled by the equilibrium of the driving pressure gradient force and the Coriolis force. The resulting wind is called geostrophic wind. In the atmospheric boundary layer the friction force causes a deviation of the wind direction to the left (on the northern hemisphere).

Specifically at Vienna airport abrupt vertical wind direction changes are related to vertical air mass boundaries. Typically southeasterly winds at lower altitudes are eroded by westerly winds from above. This may lead to situations where favorable headwind conditions in ground proximity are combined with adverse tailwinds aloft.

Figure 13 illustrates a pronounced headwind situation with up to $11 \mathrm{~m} / \mathrm{s}$ and a crosswind component below $400 \mathrm{~m}$ altitude with a maximum of $3.8 \mathrm{~m} / \mathrm{s}$ prevailing on 18 November 2017 during the time block starting at 21 UTC. The headwind in ground proximity of about $4 \mathrm{~m} / \mathrm{s}$ is not strong enough to transport the rebounding A319 wake vortices sufficiently far against flight direction such that the flight corridor would be cleared from the vortices. However, the crosswind of $2.6 \mathrm{~m} / \mathrm{s}$ advects the safety area out of the flight corridor at $62 \mathrm{~s}$. The flight corridor in gate 1 is freed from the safety corridor only at $79 \mathrm{~s}$ where the headwind strengthens the effective vortex descent of the barely attenuated vortices (see Figure 14).
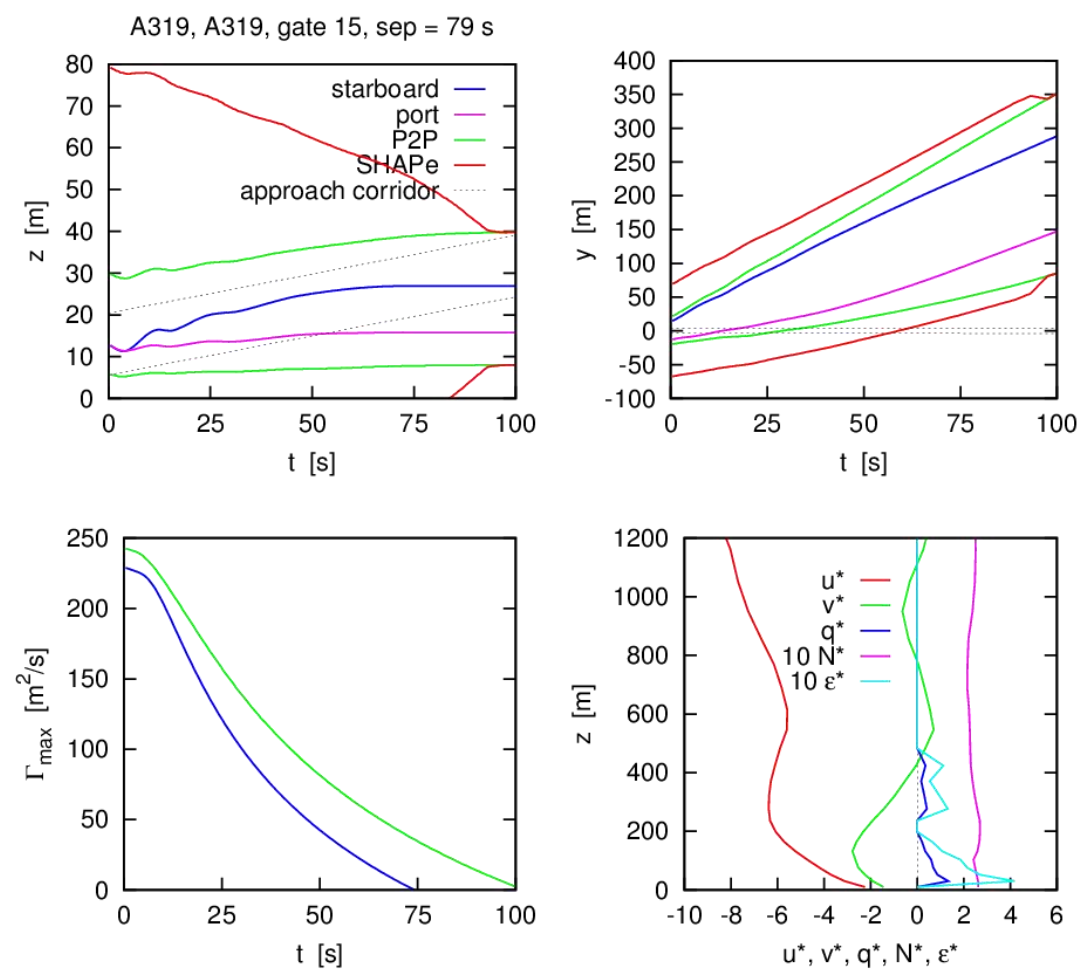

Figure 13 WSVS prediction of wake vortex parameters, safety areas and meteorological parameters for a leading A319 followed by an A319 in gate 15 . 

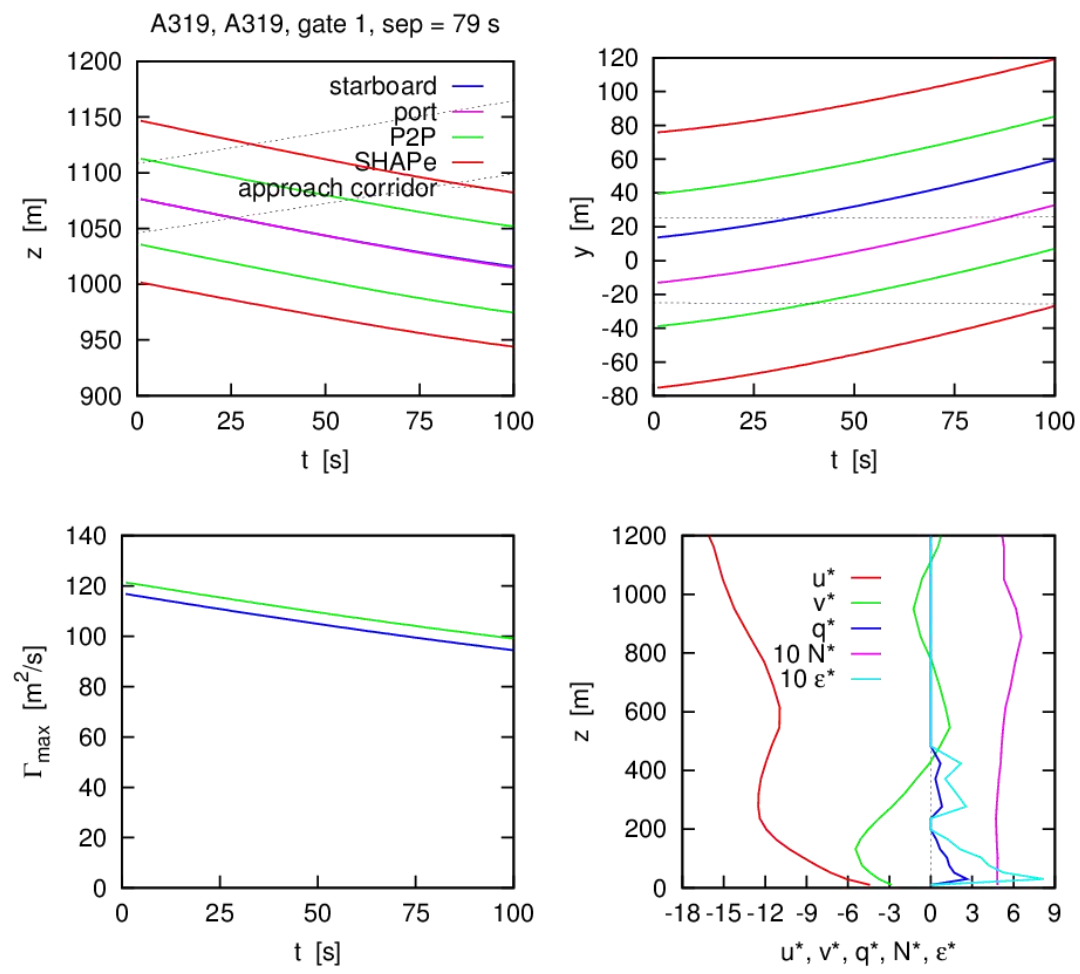

Figure 14 WSVS prediction of wake vortex parameters, safety areas and meteorological parameters for a leading A319 followed by an A319 in gate 1.

\section{Statistics of Wind Effects on Aircraft Separations}

As described in the previous sections, the minimum wake turbulence separations predicted by the WSVS dominantly depend on the wind conditions as well as the wake vortex characteristics. The latter in turn depend on the aircraft type and its operating conditions and also the follower aircraft type which impacts the size of the safety area. Figure 15 shows mean values of the separation times, corresponding to the instant of time when the last gate is cleared by the safety areas of the wake vortices, of all 78.119 aircraft pairings as a function of headwind and crosswind speeds. Wind speeds are taken from the reference height of the last unblocked gate (see Table 1). Because the data base mainly contains medium weight class aircraft, these mean separations correspond exclusively to landings with medium weight class leader and follower aircraft. Headwinds are denoted by negative values of $u$. Wind conditions not covered by landings are denoted by separation times of $0 \mathrm{~s}$.

Obviously crosswinds are most efficient in advecting the vortices away from the flight corridor. On average, crosswinds above $\pm 2 \mathrm{~m} / \mathrm{s}$ are sufficient to reduce separation times to about $1 \mathrm{~min}$. At typical aircraft speeds in final approach of $160 \mathrm{kt}$ and zero headwind component, a time separation of 1 min corresponds to approximately $2.5 \mathrm{~nm}$, the minimum radar separation applicable when wake vortex separation is not required. As explained in section IV, headwinds accelerate the unblocking of the approach corridor by advecting the vortices along the direction of the sloping glide path. So headwind advection can be considered to act as an increased vortex descent speed. Tailwinds have the opposite effect for what reason maximum average separations of $150 \mathrm{~s}$ occur around tailwinds of $6 \mathrm{~m} / \mathrm{s}$ with crosswinds close to zero. The effect of headwinds on acceptable aircraft separations, however, is indirect and thus small. Only for headwinds stronger than $-15 \mathrm{~m} / \mathrm{s}$ the average separation times drop below $1 \mathrm{~min}$. 


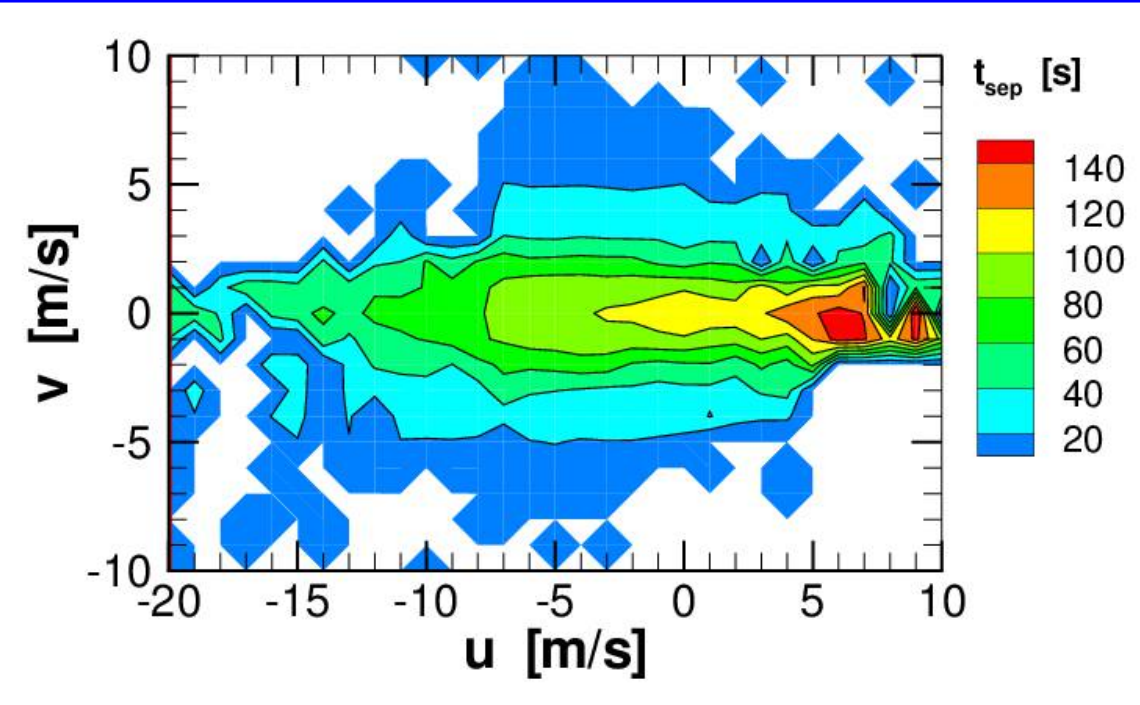

Figure 15 WSVS mean separations dependent on wind speeds in last cleared gates.

The count of medium aircraft behind heavy aircraft amounts to only 4417 or $5.7 \%$ of all landings. As a consequence, the corresponding mean separation times plot shown in Figure 16 is less smooth and covers smaller ranges of wind speeds. For heavy-medium pairings crosswinds of at least $\pm 4 \mathrm{~m} / \mathrm{s}$ are needed to consistently reduce mean separation times to about $1 \mathrm{~min}$. The data base is not big enough to derive a headwind above which aircraft separations fall below one min. At tailwinds of $6 \mathrm{~m} / \mathrm{s}$ combined with neglectable crosswinds mean time separations arrive at the adjusted maximum prediction time of the WSVS of $180 \mathrm{~s}$.

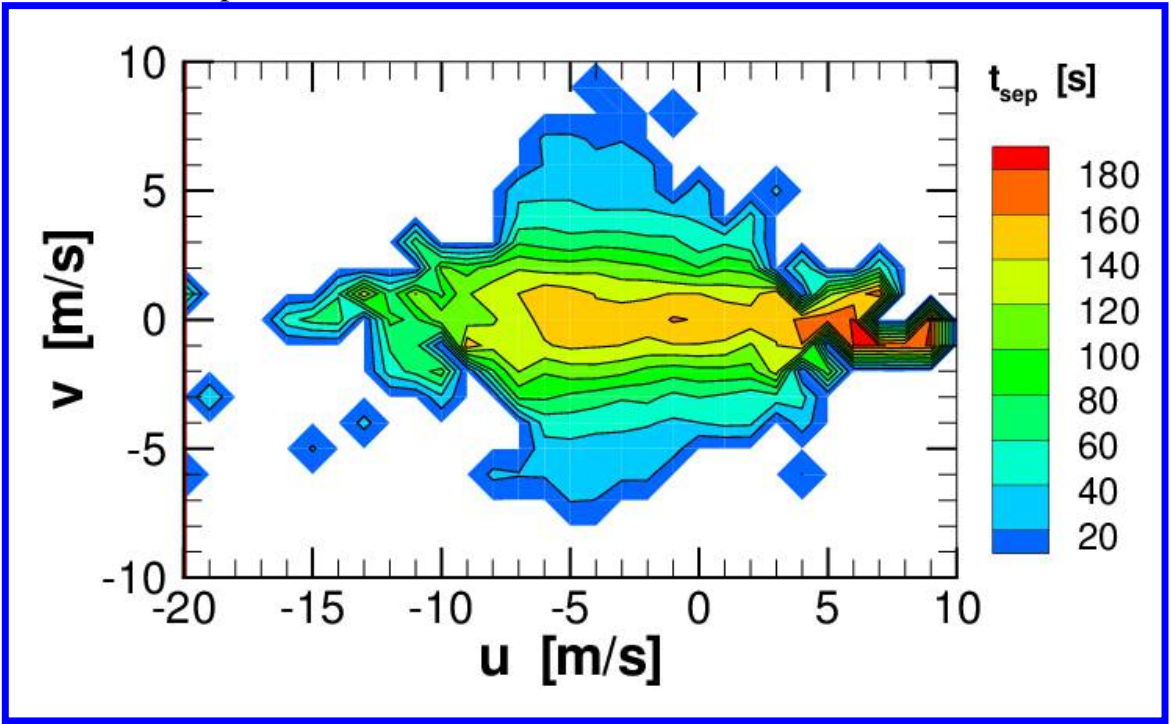

Figure 16 WSVS mean separations dependent on wind speeds in last cleared gates for medium aircraft behind heavies. 


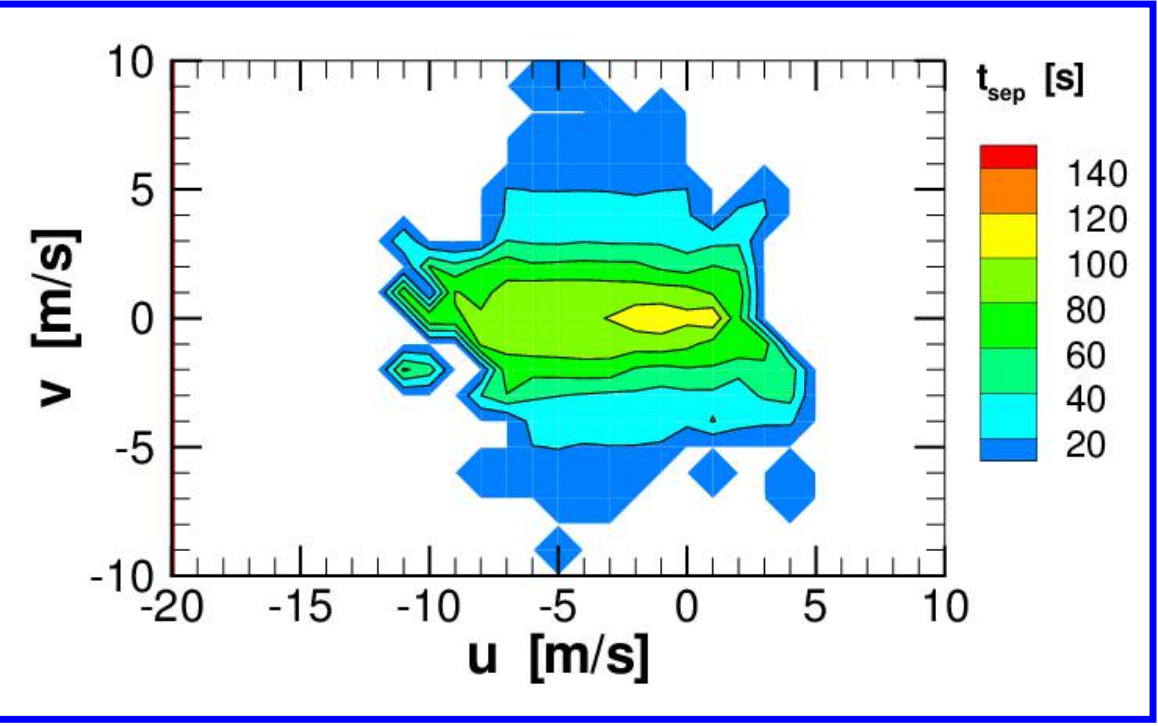

Figure 17 WSVS mean separations dependent on wind speeds in gate 15, closest to the ground.

In $72 \%$ of the cases, the wake behavior in gate 15 closest to the ground controls minimum wake turbulence separations because in close ground proximity vortices cannot descend below the flight corridor and lateral vortex advection of the luff vortex is partly compensated by vortex induced lateral propagation ${ }^{19,27}$ (cf. e.g. Figure 9). Figure 17 illustrates the wind conditions when gate 15 is cleared last by the safety areas. Due to ground proximity the data base does not contain situations with winds above $11 \mathrm{~m} / \mathrm{s}$ and tailwinds are limited to $4 \mathrm{~m} / \mathrm{s}$. The maximum mean separation time of $116 \mathrm{~s}$ occurs at a tailwind of $1 \mathrm{~m} / \mathrm{s}$ and zero crosswinds. Due to the interaction with the ground the mean crosswind needed to enable aircraft separations below $1 \mathrm{~min}$ amounts to $3 \mathrm{~m} / \mathrm{s}$, which is $1 \mathrm{~m} / \mathrm{s} \mathrm{more}$ than in Figure 15.

Figure 18 depicts the $0^{\text {th }}, 5^{\text {th }}, 25^{\text {th }}, 50^{\text {th }}, 75^{\text {th }}, 95^{\text {th }}$ and $100^{\text {th }}$ percentiles of the predicted WSVS separations as a function of the crosswind speeds in the last cleared gates for all landings. In the zero crosswind class, the whole range of separation times between $10 \mathrm{~s}$ and $180 \mathrm{~s}$ is present depending on aircraft type combinations and meteorological conditions, where headwind effects contribute dominantly to that large spread. The median value denoted by a red dash amounts to $99 \mathrm{~s}$. As seen already in Figure 15, the median separation times drop below $60 \mathrm{~s}$ at crosswinds of about $\pm 2 \mathrm{~m} / \mathrm{s}$, a crosswind speed where the maximum separation times are still cut off at $180 \mathrm{~s}$, due to the adjusted maximum prediction time of the WSVS. Crosswinds of at least $\pm 3 \mathrm{~m} / \mathrm{s}( \pm 5 \mathrm{~m} / \mathrm{s})$ are necessary to separate $95 \%$ (all) of the landing aircraft by less than $1 \mathrm{~min}$. Crosswinds of $\pm 9 \mathrm{~m} / \mathrm{s}$ blow the safety areas out of the flight corridor in less than $15 \mathrm{~s}$. 


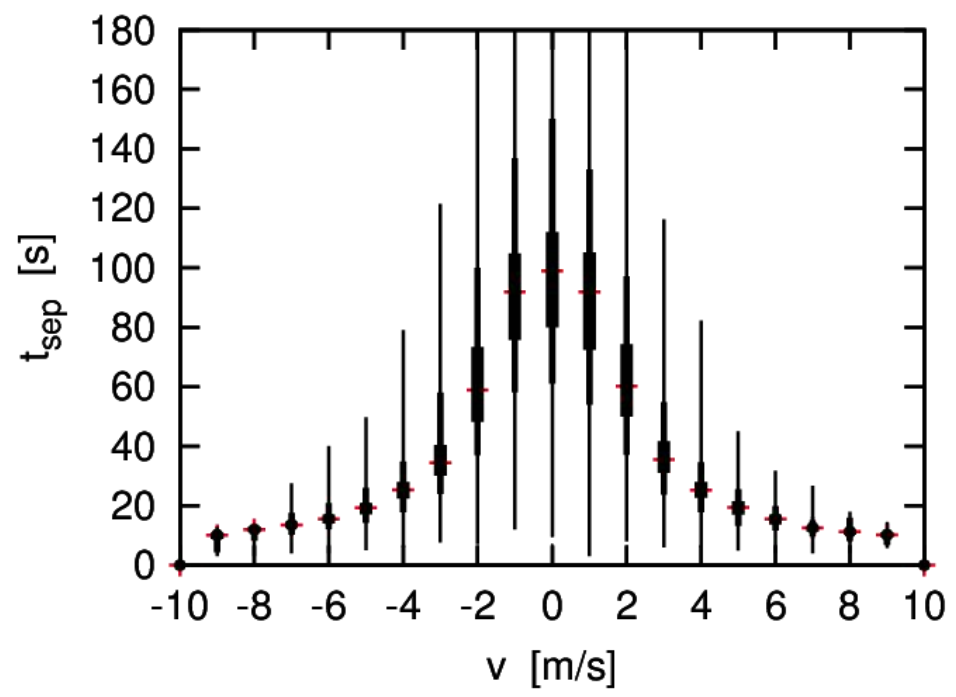

Figure 18 Predicted WSVS separations dependent on crosswind speeds in last cleared gates; $0^{\text {th }}, 5^{\text {th }}, 25^{\text {th }}, 50^{\text {th }}, 75^{\text {th }}$, $95^{\text {th }}$ and $100^{\text {th }}$ percentiles.

Figure 19 shows the same dependencies as Figure 18 for medium aircraft behind heavies. Since the calculation of the $5^{\text {th }}$ and the $95^{\text {th }}$ percentiles require at least 20 cases, the maximum crosswinds are limited to $\pm 6 \mathrm{~m} / \mathrm{s}$. The maximum separation values in Figure 18 and Figure 19 are identical because they are controlled by medium aircraft following heavies or super-heavies. However, all other separation values are substantially increased because of the higher values of initial circulation and vortex separation of the trailing vortices generated by the larger aircraft. Nevertheless, the result from Figure 18 that crosswinds of at least $\pm 5 \mathrm{~m} / \mathrm{s}$ are required to separate all of the landing aircraft by less than 1 min holds even for this class of pairings.

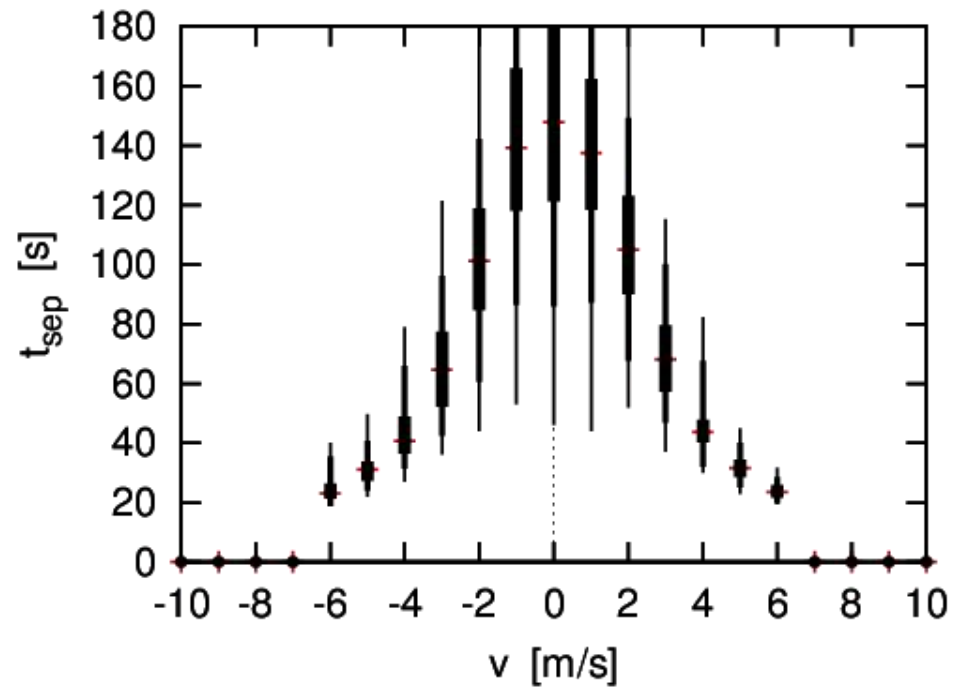

Figure 19 Predicted WSVS separations dependent on crosswind speeds in last cleared gates for medium aircraft behind heavies; $0^{\text {th }}, 5^{\text {th }}, 25^{\text {th }}, 50^{\text {th }}, 75^{\text {th }}, 95^{\text {th }}$ and $100^{\text {th }}$ percentiles.

Figure 20 delineates headwind effects on WSVS separations. For a wide range of headwind speeds the separation times vary between very small values and the adjusted maximum of $180 \mathrm{~s}$. So a headwind threshold alone is generally not suitable to reduce aircraft separations. However, the median separation times decrease almost linearly with increasing headwind speeds. In combination with other favorable parameters like crosswind, however, headwinds may contribute to some helpful reduction of separations (cf. headwind range below $-7 \mathrm{~m} / \mathrm{s}$ in Figure 15). 


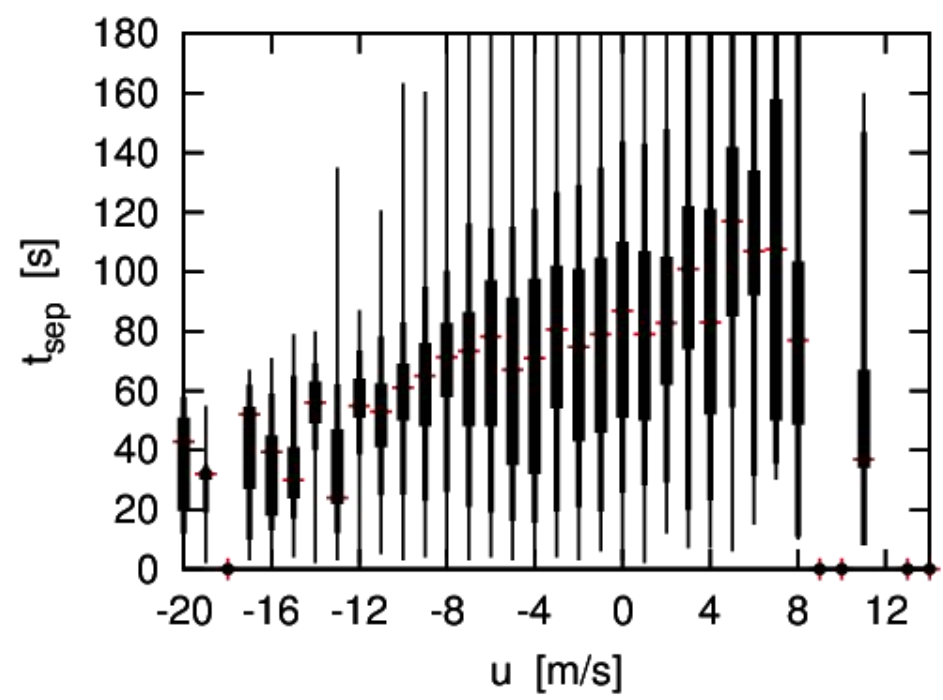

Figure 20 Predicted WSVS separations dependent on headwind speeds in last cleared gates; $0^{\text {th }}, 5^{\text {th }}, 25^{\text {th }}, 50^{\text {th }}, 75^{\text {th }}$, $95^{\text {th }}$ and $100^{\text {th }}$ percentiles.

Figure 21 shows statistics of the predicted WSVS separations dependent on the minimum crosswind magnitude within the entire wind profile within the height range covered by the gates. On average, the minimum crosswind within the whole vertical crosswind profile needed to allow for a certain aircraft separation is only slightly lower than the crosswind in the gate that is cleared last. This means that for most cases the last cleared gate corresponds to the gate residing closest to the crosswind minimum within the considered height range. Accordingly, the percentiles for the aircraft separations at a given crosswind minimum are slightly lower than those interpolated to the relevant gate (cf. Figure 18).

From Figure 21 it can be concluded that crosswind magnitudes of at least $5 \mathrm{~m} / \mathrm{s}$ all along a vertical crosswind profile are sufficient to separate all landing aircraft by less than $1 \mathrm{~min}$. However, this favorable situation, where aircraft separations could be reduced significantly based on a simple crosswind criterion, prevails only during $3.7 \%$ of the investigated cases.

An analysis for departures at Frankfurt airport yields a crosswind threshold of $8 \mathrm{kt}(4.1 \mathrm{~m} / \mathrm{s})$ measured at an altitude of $10 \mathrm{~m}$ above ground to reduce the associated separation distances between heavy leader aircraft and medium follower aircraft from the required $2 \mathrm{~min}$ to only $1 \mathrm{~min}^{29,30}$. The departure study stipulated that for $1 \mathrm{~min}$ separations under favorable crosswind conditions the encounter risks (derived from encounter frequency and severity) were lower than those in a reference scenario at 2 min separations.

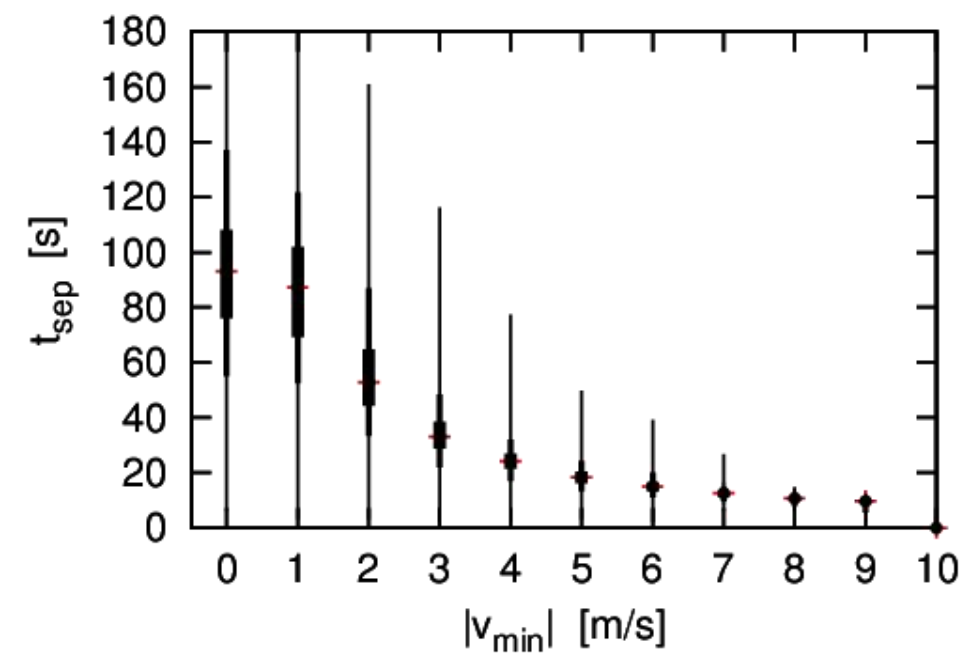

Figure 21 Predicted WSVS separations dependent on minimum crosswind magnitude $; 0^{\text {th }}, 5^{\text {th }}, 25^{\text {th }}, 50^{\text {th }}, 75^{\text {th }}, 95^{\text {th }}$ and $100^{\text {th }}$ percentiles. 


\section{Separation-Reduction Potential}

Figure 22 displays the distribution of temporal separations suggested by the WSVS for all 78.119 aircraft pairings. The fraction of landings below minimum radar separation (corresponding to approximately $60 \mathrm{~s}$ ) amounts to $37 \%$. Figure 23 displays the predicted aircraft separations for heavy vortex generators and medium follower aircraft. In $66 \%$ of landings separations could be reduced below a value of $125 \mathrm{~s}$ being representative for the $5 \mathrm{~nm}$ separation prescribed by ICAO according to Ref. 6 . The fraction of landings where minimum radar separation of $60 \mathrm{~s}$ could be applied amounts to $18 \%$.

The criterion that crosswinds of $5 \mathrm{~m} / \mathrm{s}$ or stronger prevail along the whole altitude range covered by the WSVS also allows to reduce separations to $60 \mathrm{~s}$ without installation of any wake vortex advisory system (see Figure 21). However, in the Vienna database such favorable winds are blowing only during $3.7 \%$ of the time.

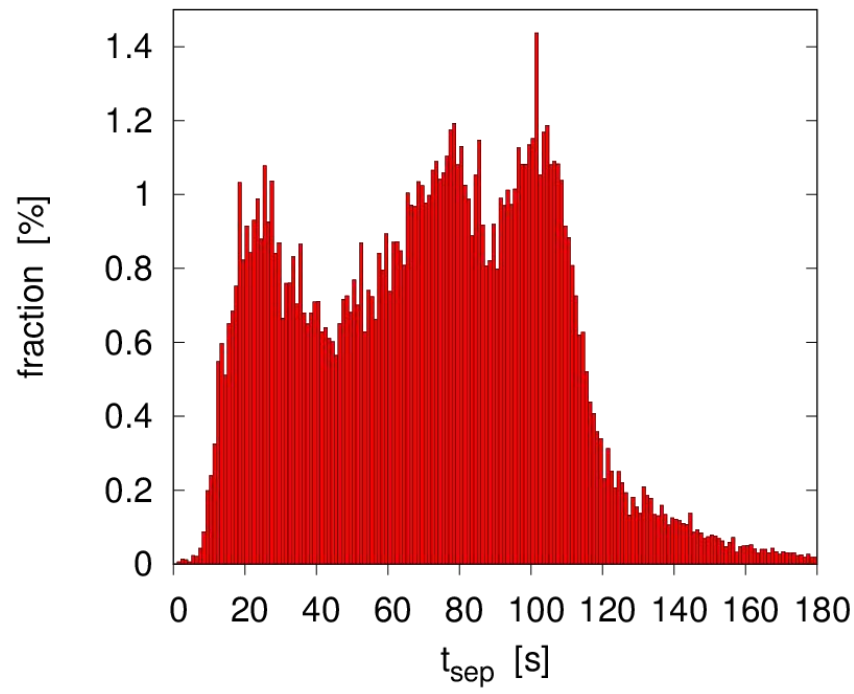

Figure 22 Distribution of temporal aircraft separations suggested by the WSVS.

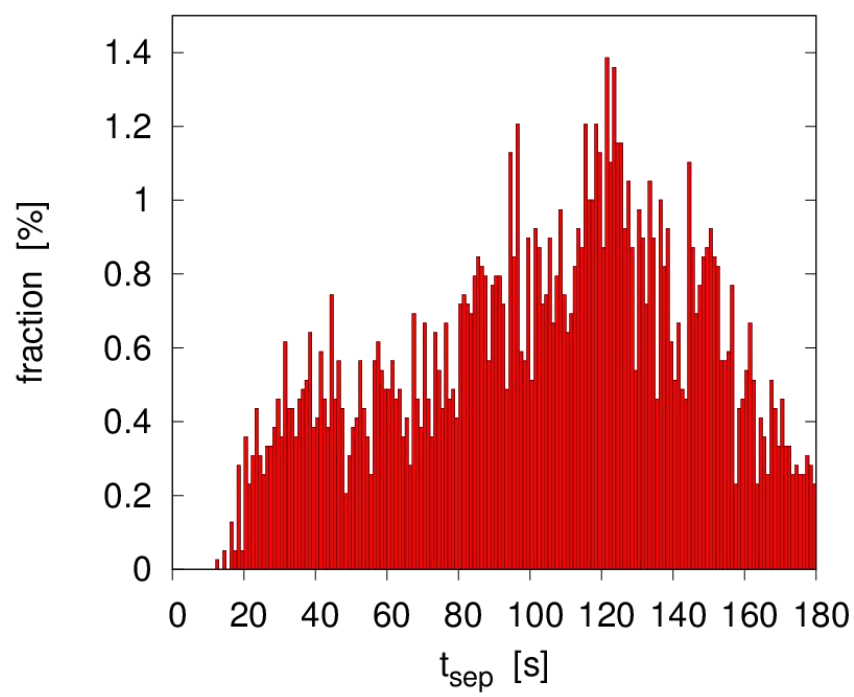

Figure 23 Distribution of temporal aircraft separations suggested by the WSVS for heavy/medium aircraft sequences. 
Table 2 lists the spatial separations foreseen by the RECAT-EU scheme ${ }^{4}$. It further specifies the fraction of time when WSVS predictions would allow reducing the RECAT-EU separations to minimum radar separation of $60 \mathrm{~s}$ and the respective number of landings in brackets. On average, this is the case in $23 \%$ of the landings. The fraction of the total considered traffic where RECAT-EU separations could be reduced to minimum radar separation amounts to $8 \%$.

The Vienna database does not contain landings with leading category A and following categories A or C. For A leaders and followed by category B or F none of the separations of the few recorded landings could be reduced below $60 \mathrm{~s}$. For the other category combinations, the fraction of times supporting minimum radar separation vary between $9 \%$ and $57 \%$. For a given follower category, the fraction of reduced separations decreases with increasing weight and span of the leading aircraft types.

Table 2 RECAT-EU distance-based separation minima and fraction of minimum radar separations suggested by the WSVS with respective number of landings in the Vienna dataset in brackets.

\begin{tabular}{ccccccc}
\hline \hline Follower & Super Heavy & Upper Heavy & Lower Heavy & Upper Med. & Lower Med. & Light \\
Leader & $\mathrm{A}$ & $\mathrm{B}$ & $\mathrm{C}$ & $\mathrm{D}$ & $\mathrm{E}$ & $\mathrm{F}$ \\
\hline Super Heavy & $3 \mathrm{~nm}$ & $4 \mathrm{~nm}$ & $5 \mathrm{~nm}$ & $5 \mathrm{~nm}$ & $6 \mathrm{~nm}$ & $8 \mathrm{~nm}$ \\
A & - & $0 \%(4)$ & - & $9 \%(105)$ & $15 \%(33)$ & $0 \%(5)$ \\
Upper Heavy & - & $3 \mathrm{~nm}$ & $4 \mathrm{~nm}$ & $4 \mathrm{~nm}$ & $5 \mathrm{~nm}$ & $7 \mathrm{~nm}$ \\
B & - & $17 \%(342)$ & $13 \%(175)$ & $19 \%(1499)$ & $14 \%(942)$ & $29 \%(80)$ \\
Lower Heavy & - & - & $3 \mathrm{~nm}$ & $3 \mathrm{~nm}$ & $4 \mathrm{~nm}$ & $6 \mathrm{~nm}$ \\
C & - & - & $19 \%(136)$ & $23 \%(830)$ & $18 \%(651)$ & $32 \%(19)$ \\
Upper Medium & - & - & - & - & - & $5 \mathrm{~nm}$ \\
D & - & - & - & - & - & $36 \%(1007)$ \\
Lower Medium & - & - & - & - & - & $4 \mathrm{~nm}$ \\
E & - & - & - & - & - & $44 \%(486)$ \\
Light & - & - & - & - & - & $3 \mathrm{~nm}$ \\
F & - & - & - & - & - & $57 \%(49)$ \\
\hline \hline
\end{tabular}

\section{Conclusion}

This study assesses dynamic pairwise wake vortex separations for approach and landing at Vienna airport using the Wake Vortex Prediction System WSVS.

As a first step, a Monte Carlo simulation study demonstrates that the WSVS is well adjusted to a reasonable level of safety. The simulation study evaluates the probability that wake vortices linger within a defined radius around the follower aircraft and compares this probability to measurement data collected at five major international airports. It is found that for WSVS predictions wake vortices in ground proximity still reside within a distance of $25 \mathrm{~m}$ to the follower aircraft in $0.25 \%$ of the landings. This is about six times less frequent than the $1.5 \%$ estimated by the independent lidar data analysis representing the daily routine without a wake vortex advisory system.

The WSVS has been applied to nine months of traffic and weather prediction data collected at Vienna International Airport. Selected case studies provide overviews on landing rates, meteorological conditions, spatial and temporal aircraft separations as actually flown and predicted by the WSVS. Favorable wind conditions allow reducing aircraft separations to minimum radar separation for periods of several hours or even complete days.

The effects of headwind and crosswind as well as the aircraft type combination on the unblocking of the different prediction planes (gates) of the WSVS are discussed in detail on the basis of selected individual probabilistic wake vortex predictions and related safety areas. The effect of headwinds on acceptable aircraft separations is fairly small. Intermediate headwinds accelerate the unblocking of the inclined approach corridor but close to the ground vortex descent is inhibited such that, in the absence of sufficiently strong crosswinds, aircraft separation is largely controlled by vortex decay. Only for headwinds stronger than $-15 \mathrm{~m} / \mathrm{s}$, the average separation time drops below 1 min. 
Strong crosswind constitutes the most efficient mechanism to unblock the approach corridor. Here typically either the highest gate controls the aircraft separation, because there the approach corridor is the widest, or the lowest gate is unblocked at last, because of the vortex divergence driven by the interaction with the ground surface. Crosswinds above $\pm 2 \mathrm{~m} / \mathrm{s}$ are sufficient to reduce median separation times to about $1 \mathrm{~min}$. However, crosswinds of at least $\pm 3 \mathrm{~m} / \mathrm{s}( \pm 5 \mathrm{~m} / \mathrm{s})$ are necessary to separate $95 \%$ (all) of the landing aircraft by less than $1 \mathrm{~min}$. Crosswinds of $\pm 9 \mathrm{~m} / \mathrm{s}$ blow the safety areas out of the flight corridor in less than $15 \mathrm{~s}$. A $5 \mathrm{~m} / \mathrm{s}$ crosswind threshold blowing all along the glide path supports separations by less than 1 min without the need to operate a wake vortex advisory system. However, such favorable wind conditions prevail only during $3.7 \%$ of the investigated cases. The operation of the WSVS could increase this percentage substantially to $37 \%$ of the landings.

For $66 \%$ of the heavy vortex generators and medium follower aircraft, the WSVS could reduce landing separations below a value of $125 \mathrm{~s}$ (corresponding to the prescribed ICAO separation of $5 \mathrm{~nm}$ ) and the fraction of landings where minimum radar separation (approximated by $60 \mathrm{~s}$ ) could be applied amounts to $18 \%$. In $23 \%$ of landings, for which RECAT-EU vortex separations apply, or $8 \%$ of all landings, a further reduction to minimum radar separation is found to be possible while ensuring safety.

Based on this study's findings, we conclude that the installation of the WSVS for operational purposes may substantially increase the number of aircraft landing on a runway per hour under suitable weather conditions without compromising safety. The SESAR2020 "plate line" measurement campaign to be conducted at Vienna airport from May to September 2019, will help to further substantiate these results with lidar observations of wake vortex behavior.

\section{Acknowledgments}

The work was funded by the Federal Ministry of the Republic of Austria for Transport, Innovation and Technology project "MET Potentiale im Arrival- und Departure Management - MET4LOWW" and the German Aerospace Research Center (DLR) project "Wetteroptimierter Luftverkehr".

\section{References}

' Hallock, J.N., Holzäpfel, F., “A Review of Recent Wake Vortex Research for Increasing Airport Capacity”, Progress in Aerospace Sciences, Vol. 98, 2018, pp. 27-36, https://doi.org/10.1016/j.paerosci.2018.03.003.

${ }^{2}$ European Aviation in 2040 - Challenges of Growth, EUROCONTROL, 2018, p. 40, https://www.eurocontrol.int/articles/challenges-growth.

${ }^{3}$ Cheng, J., Tittsworth, J., Gallo, W., Awwad, A., "The Development of Wake Turbulence Recategorization in the United States," AIAA Paper 2016-3434, June 2016, p. 12.

${ }^{4}$ RECAT-EU, European Wake Turbulence Categorisation and Separation Minima on Approach and Departure, EUROCONTROL, 2015, p. 32.

${ }^{5}$ Holzäpfel, F., Gerz, T., Frech, M., Tafferner, A., Köpp, F., Smalikho, I., Rahm, S., Hahn, K.-U., Schwarz, C., "The Wake Vortex Prediction and Monitoring System WSVBS - Part I: Design," Air Traffic Control Quarterly, Vol. 17, No. 4, 2009, pp. 301-322.

${ }^{6}$ Gerz, T., Holzäpfel, F., Gerling, W., Scharnweber, A., Frech, M., Kober, K., Dengler, K., Rahm, S., "The Wake Vortex Prediction and Monitoring System WSVBS Part II: Performance and ATC Integration at Frankfurt Airport," Air Traffic Control Quarterly, Vol. 17, No. 4, 2009, pp. 323-346.

>7 Holzäpfel, F. , Dengler, K., Gerz, T., Schwarz, C., "Prediction of Dynamic Pairwise Wake Vortex Separations for Approach and Landing," AIAA Paper 2011-3037, 3rd AIAA Atmospheric Space Environments Conference, 27-30 June 2011, Honolulu, Hawaii, 15 pages.

${ }^{8}$ Sharman, R. Tebaldi, C., Wiener, G., Wolff, J., "An Integrated Approach to Mid- and Upper-Level Turbulence Forecasting," Weather and Forecasting, Vol. 21, 2006, pp. 268-287, DOI: http://dx.doi.org/10.1175/WAF924.1.

${ }^{9}$ Colson, D., Panofsky, H.A., “An index of clear air turbulence," Quarterly Journal of the Royal Meteorological Society, Vol. 91, Issue 390, 1965, pp. 507-513, DOI: 10.1002/qj.49709139010.

${ }^{10}$ ICAO, Manual on Mode S Specific Services, Doc 9688, AN/952, 2 ${ }^{\text {nd }}$ Edition, 2004.

${ }^{11}$ Donaldson, C. D., Bilanin, A. J., "Vortex Wakes of Conventional Aircraft,” NATO Rept. AG-204, Paris, 1975.

${ }^{12}$ Delisi, D.P., Pruis, M.J., Wang, F.Y., Lai, D.Y., "Estimates of the Initial Vortex Separation Distance, $\mathrm{b}_{0}$, of Commercial Aircraft from Pulsed Lidar Data," AIAA Paper 2013-0365, 51st AIAA Aerospace Sciences Meeting including the New Horizons Forum and Aerospace Exposition, 07 10 January 2013, Grapevine, Texas, 2013, 10 pages.

${ }^{13}$ Eurocontrol, FAA, Technical Report to Support the Safety Case for the Re-Categorization of ICAO Wake Turbulence Standards, 2011, 117 pages.

${ }^{14}$ BADA, User Manual for the Base of Aircraft Data (BADA) Revision 3.11, EEC Technical/Scientific Report No. 13/04/16-01, EUROCONTROL, May 2013, 109 pages. http://upcommons.upc.edu/bitstream/handle/2099.1/24342/AnnexI.pdf?sequence=2

$\checkmark{ }^{15}$ Holzäpfel, F., "Analysis of potential wake vortex encounters at a major European airport," Aircraft Engineering and Aerospace Technology, Vol. 89, Issue 5, 2017, pp. 634-643, http://dx.doi.org/10.1108/AEAT-01-2017-0043.

${ }^{16}$ Holzäpfel, F., "Probabilistic Two-Phase Wake Vortex Decay and Transport Model," Journal of Aircraft, Vol. 40, pp. 323-331, 2003.

${ }^{17}$ Holzäpfel, F., Robins, R.E., "Probabilistic Two-Phase Aircraft Wake-Vortex Model: Application and Assessment", Journal of Aircraft, Vol. 41, pp. 1117-1126, 2004. 
${ }^{18}$ Holzäpfel, F., "Probabilistic Two-Phase Aircraft Wake-Vortex Model: Further Development and Assessment", Journal of Aircraft, Vol. 43, pp. 700-708, 2006.

${ }^{19}$ Holzäpfel, F., Steen, M., “Aircraft Wake-Vortex Evolution in Ground Proximity: Analysis and Parameterization”, AIAA Journal Vol. 45, pp. 218-227, 2007.

${ }^{20}$ Holzäpfel, F., "Effects of Environmental and Aircraft Parameters on Wake Vortex Behavior," Journal of Aircraft, Vol. 51, 2014, pp. 14901500, doi: 10.2514/1.C032366.

${ }^{21}$ Hahn, K.-U., Schwarz, C., Friehmelt, H., “A Simplified Hazard Area Prediction (SHAPe) Model for Wake Vortex Encounter Avoidance”, 24th International Congress of Aeronautical Sciences, Yokohama (Japan), 29 August - 3 September 2004, ICAS, 24th International Congress of Aeronautical Sciences Proceedings, 2004.

${ }^{22}$ Schwarz, C.W., Hahn, K.-U., "Full-flight simulator study for wake vortex hazard area investigation", Aerospace Science and Technology, Vol. 10, pp. 136-143, 2006, doi: 10.1016/j.ast.2005.09.005.

${ }^{23}$ Schwarz, C.W., Hahn, K.-U., Fischenberg, D., "Wake Encounter Severity Assessment Based on Validated Aerodynamic Interaction Models," AIAA ASE Conference, 2010.

${ }^{24}$ Körner, S., Holzäpfel, F., "Assessment of the Wake-Vortex Encounter Probability on Final Approach based on Lidar Measurements," Journal of Aircraft, accepted for publication, 2018, https://doi.org/10.2514/1.C035252.

25 "Rules of the Air," Annex 2 to the Convention on International Civil Aviation, 10th ed., Vol. 10, ICAO, Chicago, IL, July 2005, https://www.icao.int/Meetings/anconf12/Document\%20Archive/an02_cons\%5B1\%5D.pdf.

${ }^{26}$ Gurke, T., Lafferton, H., "The development of the wake vortex warning system for Frankfurt Airport: Theory and implementation," Air Traffic Control Quarterly, Vol. 5, pp. 3-29, 1997.

${ }^{27}$ Holzäpfel, F., Tchipev, N., Stephan, A., "Wind Impact on Single Vortices and Counterrotating Vortex Pairs in Ground Proximity," Flow, Turbulence and Combustion, Vol. 97, Issue 3, 2016, pp. 829-848, http://dx.doi.org/10.1007/s 10494-016-9729-2.

${ }^{28}$ Holzäpfel, F., Stephan, A., Heel, T., Körner, S., "Enhanced Wake Vortex Decay in Ground Proximity Triggered by Plate Lines," Aircraft Engineering and Aerospace Technology, Vol. 88, Issue 2, 2016, pp. 206-214.

${ }^{29}$ Holzäpfel, F., Kladetzke, J., “Assessment of Wake Vortex Encounter Probabilities for Crosswind Departure Scenarios," Journal of Aircraft, Vol. 48, 2011, pp. 812-822. Doi: 10.2514/1.C000236.

${ }^{30}$ Kauertz, S., Holzäpfel, F., Kladetzke, J., "Wake Vortex Encounter Risk Assessment for Crosswind Departures," Journal of Aircraft, Vol. 49, 2012, pp. 281-291, doi: 10.2514/1.C031522. 